\title{
Changing Seasonal Predictability of Arctic Summer Sea Ice Area in a Warming Climate
}

\author{
MARikA M. Holland, LAURA LANDRUM, AND DAVID BAILEY \\ Climate and Global Dynamics Laboratory, National Center for Atmospheric Research, Boulder, Colorado \\ STEVe VAVRUS \\ Nelson Institute Center for Climatic Research, University of Wisconsin-Madison, Madison, Wisconsin
}

(Manuscript received 14 January 2019, in final form 24 April 2019)

\begin{abstract}
We use a large ensemble set of simulations and initialized model forecasts to assess changes in the initialvalue seasonal predictability of summer Arctic sea ice area from the late-twentieth to the mid-twenty-first century. Ice thickness is an important seasonal predictor of September ice area because early summer thickness anomalies affect how much melt out occurs. We find that the role of this predictor changes in a warming climate, leading to decadal changes in September ice area predictability. In January-initialized prediction experiments, initialization errors grow over time leading to forecast errors in ice thickness at the beginning of the melt season. The magnitude of this ice thickness forecast error growth for regions important to summer melt out decreases in a warming climate, contributing to enhanced predictability. On the other hand, the influence of early summer thickness anomalies on summer melt out and resulting September ice area increases as the climate warms. Given this, for the same magnitude ice thickness forecast error in early summer, a larger September ice area anomaly results in the warming climate, contributing to reduced predictability. The net result of these competing factors is that a sweet spot for predictability exists when the ice thickness forecast error growth is modest and the influence of these errors on melt out is modest. This occurs at about 2010 in our simulations. The predictability of summer ice area is lower for earlier decades, because of higher ice thickness forecast error growth, and for later decades because of a stronger influence of ice thickness forecast errors on summer melt out.
\end{abstract}

\section{Introduction}

Arctic sea ice cover has declined dramatically over the last 40 years with significant reductions in all months (e.g., Stroeve and Notz, 2018). This has increased Arctic marine access, primarily in the summer months, with consequent increases in activities like shipping within the Arctic (e.g., Theocharis et al. 2018). However, the Arctic remains a hazardous place and sea ice exhibits considerable interannual variability. Indeed, previous work indicates that the summer ice area variability is likely to increase with a thinning ice pack (Holland et al. 2008; Goosse et al. 2009; Mioduszewski et al. 2019). All of this motivates a need to better predict sea ice on seasonal to interannual time scales.

\footnotetext{
Corresponding author: Marika Holland, mholland@ucar.edu
}

Previous work has indicated that the Arctic summer ice area is predictable on these time scales (for a review see Guemas et al. 2016). This includes studies that have assessed Arctic sea ice predictability using perfect-model experiments from climate models (e.g., Blanchard-Wrigglesworth et al. 2011; Holland et al. 2011; Day et al. 2016; Tietsche et al. 2014) and statistical model analysis (e.g., Drobot et al. 2006). The predictability of summer ice conditions is due in part to long-lived ice thickness anomalies that can affect the melt out of ice during summer and hence the resulting ice area anomalies (Blanchard-Wrigglesworth et al. 2011). Indeed, seasonal sea ice forecasts have enhanced skill when improved ice thickness initialization is incorporated (Day et al. 2014; Collow et al. 2015; Dirkson et al. 2017). Other factors that can influence the melt season progression, such as the fraction of ponded ice (Schröder et al. 2014) or the timing of ice retreat 
(Stroeve et al. 2016), also provide predictability of latesummer ice conditions. These sources of predictability have allowed for skillful initialized forecasts in a number of systems (e.g., Chevallier et al. 2013; Sigmond et al. 2013; Wang et al. 2013; Msadek et al. 2014; Peterson et al. 2015), although the time scales and level of skill differ considerably across systems and are typically less than those suggested by more idealized studies, as illustrated by Bushuk et al. (2019).

With the long-term thinning of Arctic sea ice, an outstanding question is how sea ice predictability might change with changes in the mean sea ice state. Recent work highlights that the mean state of sea ice influences thermodynamic processes that, in turn, affect the sea ice response to a forcing perturbation (Massonnet et al. 2018). Previous work suggests that the predictors of summer ice area are not stationary but instead change as the sea ice thins and decreases in areal extent (Holland and Stroeve, 2011). Holland et al. (2011) explored this further in a case study using model simulations from the Community Climate System Model, version 3 (CCSM3). Using a limited number of initial states, they found that the summer ice area predictability differed with the climate state and was generally higher in a colder climate state. Additionally, Cheng et al. (2016) assessed lagged correlation, which is a diagnostic measure of predictability, in a large ensemble of simulations and found evidence of changing September ice extent predictability in the warming twenty-first century climate.

Here we build on this previous work by analyzing a large number of simulations based on the Community Earth System Model Large Ensemble (CESM-LE; Kay et al. 2015). In addition to analysis of the CESM-LE itself, we perform sets of simulations initialized with nearly identical states obtained from the CESM-LE. All simulations are initialized on January first and we perform ensemble simulation sets using initial states for every decade from 1980 to 2030 . These are so-called perfect-model simulations in that we are using the model to predict itself with near-perfect knowledge of the initial conditions. Because of this, prediction errors associated with initial condition uncertainty are exceedingly small and model structural uncertainty is not present, allowing us to obtain an estimate of the inherent predictability in the modeled system. Comparing across the different ensemble sets that we have performed allows us to assess predictability characteristics as simulated by CESM-LE and how they change with changes in the mean sea ice conditions. We assess the predictability of summer ice area and diagnose the mechanisms that contribute to changes in predictability for different initialization years.

\section{Model experiments and predictability metrics}

The CESM-LE (Kay et al. 2015) provides the control simulations for our study. The CESM-LE is a set of 40 model runs from 1920 to 2005 using historical forcings of greenhouse gas concentrations, volcanic emissions, solar variability, and changing ozone. The simulations then continue from 2006 to 2100 using the RCP8.5 scenario (Meinshausen et al. 2011; Lamarque et al. 2011). All simulations use the CESM-CAM5 model configuration (Hurrell et al. 2013) and are initialized in 1920 using nearly identical conditions that are obtained from a simulation branched from a long preindustrial (year $=1850)$ simulation and integrated from 1850 to 1920 using historical forcings. The ensemble simulations differ in a round-off level change in the initial 1920 air temperature and then diverge over time due to the chaotic nature of the climate system. Because of this divergence, the CESM-LE allows for the study of internal variability in the presence of anthropogenic forcing. As shown in multiple previous studies analyzing the CESM-LE, the internal variability is considerable in Arctic sea ice and can lead, for example, to a 20-yr window of uncertainty for when the Arctic will reach summer ice-free conditions (Jahn et al. 2016). The CESM-LE has a very good simulation of Arctic sea ice conditions when compared with observations (Labe et al. 2018) and undergoes considerable thinning and ice area loss from the late twentieth century through the twenty-first century (Holland and Landrum, 2015; Fig. 1). We use the CESM-LE to quantify the internal variability in sea ice conditions. We also use statistical analysis to assess diagnostic measures of predictability (hereafter referred to as "diagnostic predictability") of Arctic summer sea ice in the CESM-LE and how it may change in the warming climate. We assess conditions for an Arctic Ocean domain that excludes the Barents and Kara Seas and the Canadian Archipelago and for a Beaufort Sea domain as shown on Fig. 1.

To further explore the initial-value predictability of Arctic sea ice, we also perform a prediction ensemble that includes multiple sets of ensemble simulations using the CESM-LE model and initialized from CESM-LE conditions ("perfect model" experiments). For each decade from 1980 to 2030 we obtain 1 January initial conditions from four different ensemble members of the CESM-LE and for each of these four initial states, we generate 15 ensemble members. For each initial state, the 15 ensemble members differ only in a round-off level change in the initial air temperature. As discussed by Hawkins et al. (2016), the design of the ensemble, including the number of initial states and the number of 
(a)

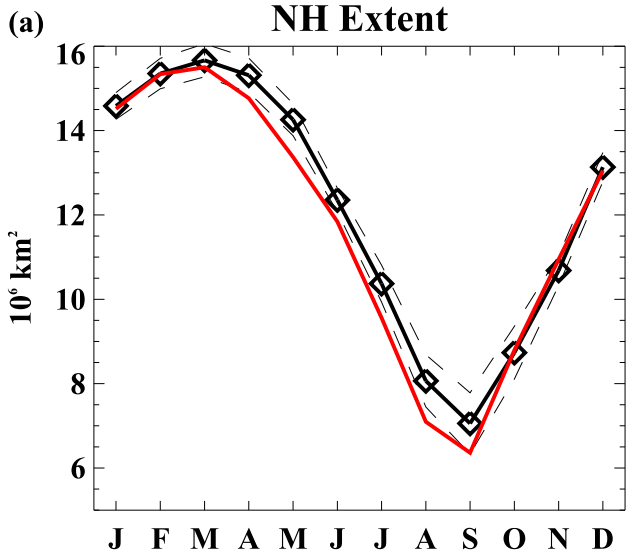

(c)

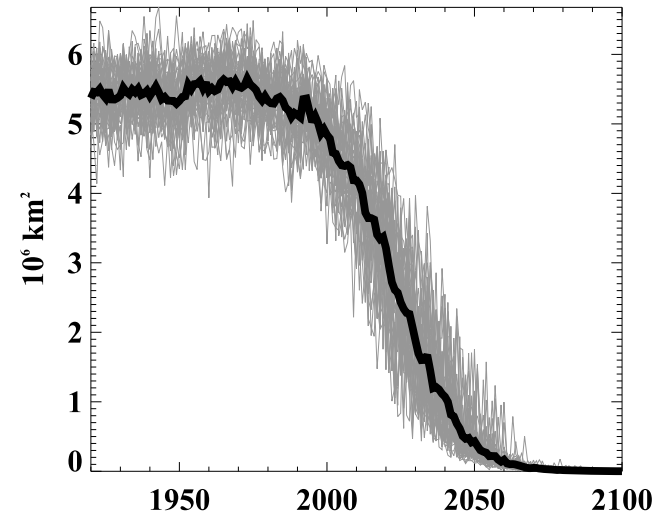

(b)

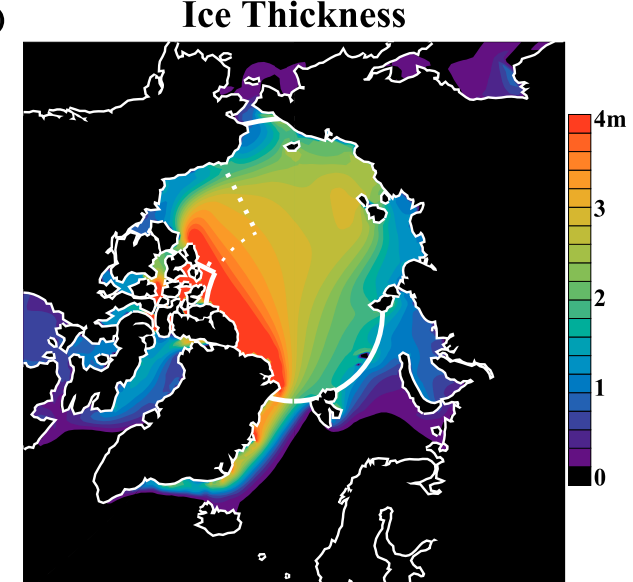

(d)

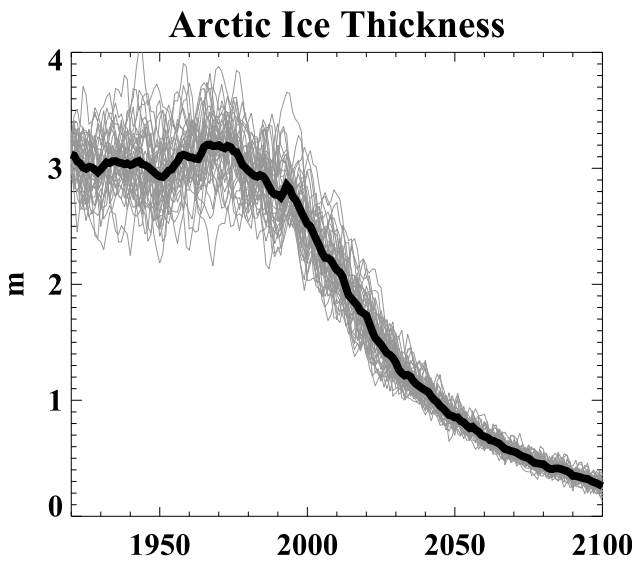

FIG. 1. Sea ice conditions in the CESM-LE, including (a) the mean monthly Northern Hemisphere ice extent from 1980 to 2010 compared with satellite observations based on the sea ice index (Fetterer et al. 2017; red curve), (b) mean 1980-2010 annual ice thickness, (c) the time series of Arctic Ocean September ice area, and (d) the time series of Arctic Ocean annual mean ice thickness. In (a), the dashed lines indicate \pm 1 standard deviation from the CESM-LE. In (c), (d) individual ensemble members are in gray and the ensemble mean is in black. In (b), the Arctic Ocean domain used for analysis is the region poleward of the thick white lines and the Beaufort Sea domain used for analysis is shown by the dotted white line.

ensemble members, affects how reliably forecast skill can be quantified. Our choice here of four initial states allows us to sample initial conditions within the internal variability of the CESM-LE at each decade. While additional initial states would allow for a better representation of that internal variability, four states provide a reasonable compromise between the reliable assessment of seasonal predictability and computational resource limitations. Our simulations are integrated for 1 year in length to assess seasonal predictability. The 1 January initialization date and the exact years of initialization $(1980,1990,2000,2011,2021$, and 2030) were chosen because of the model restart availability.

By comparing the spread across the initialized ensemble simulations to the spread expected from internal variability as obtained from the CESM-LE, we are able to assess initial-value predictability in the system. For example, Fig. 2a shows the time series of sea ice volume in the Arctic Ocean from the 1980 ensemble sets and the range of values simulated for the same time period from the CESM-LE. This is quantified further by assessing the time evolution of the across-ensemble variance in ice volume compared to the CESM-LE (Fig. 2b). For the case of ice volume in 1980, the initialized simulations retain considerably smaller variance than that expected from internal variability. This indicates that the 1 January initial state provides predictive capability for this variable for at least a year. To further formalize the associated predictability, we use the metric of potential prognostic predictability (PPP; e.g., Pohlmann et al. 2004; Hawkins et al. 2016). PPP essentially quantifies the spread across the initialized ensemble predictions relative to the spread of internal variability. It is defined as 
(a)

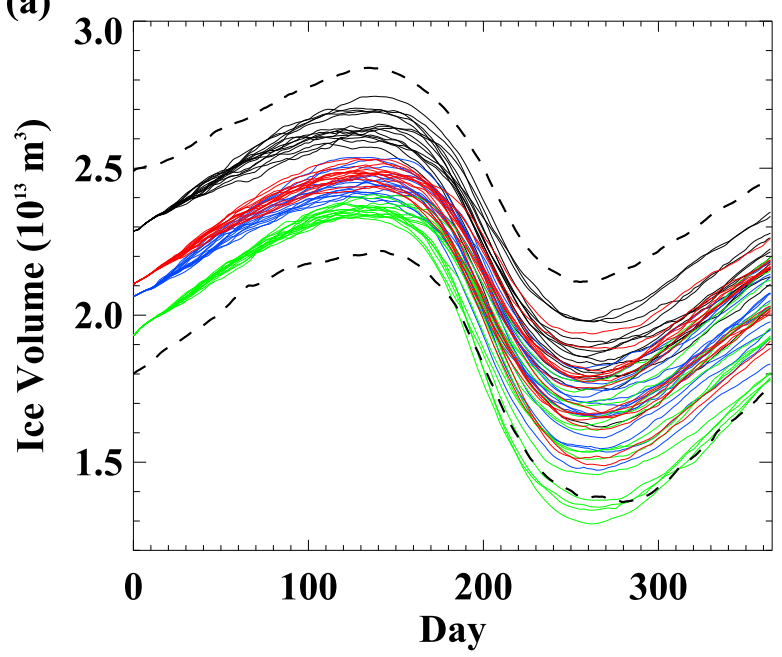

(b)

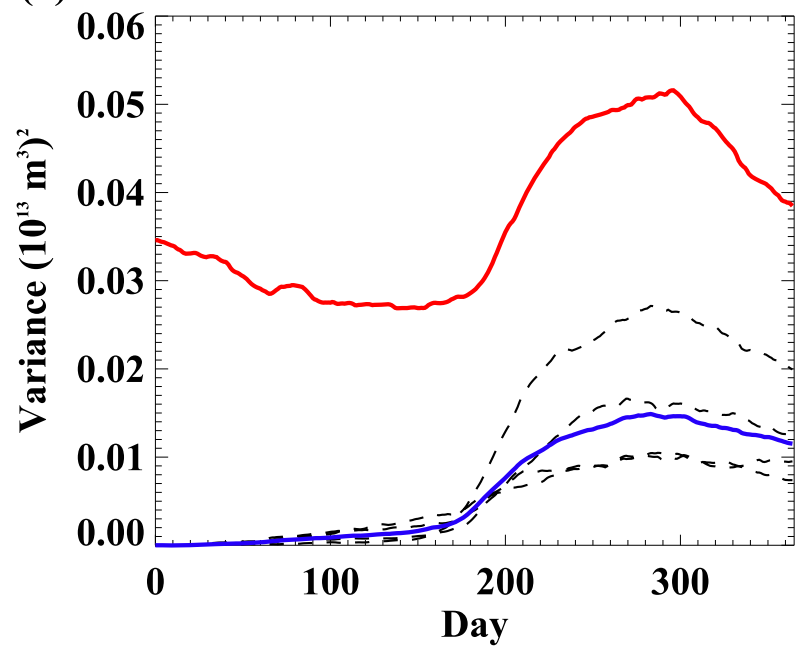

FIG. 2. (a) Arctic Ocean sea ice volume in the 1980 ensemble sets. The range of simulated volume from the 40 members of the CESM-LE for year 1980 is shown by the dashed lines. The colored lines show simulations for the four ensemble sets that have distinct initial conditions taken from different simulations of the CESMLE. (b) The variance of the Arctic Ocean ice volume across the members of the prediction ensembles (blue line, with individual sets shown as the dashed lines) and across the 40 members of the CESM-LE at year 1980 (red). The CESM-LE values provide a measure of the variance associated with internal variability in 1980.

$$
\mathrm{PPP}=1-\frac{\left\langle\left(x_{i j}-\bar{x}_{j}\right)^{2}\right\rangle_{i, j}}{\left\langle\sigma_{j}^{2}\right\rangle_{j}},
$$

where $x_{i j}$ is the variable of interest (e.g., ice area) for the $i$ th ensemble member of the $j$ th initialization state, $\bar{x}_{j}$ is the ensemble mean of the $j$ th prediction ensemble, and $\sigma_{j}^{2}$ is a measure of the internal variability and is equal to the variance from the control simulation (in our case the CESM-LE) at the time of the prediction ensemble. The \langle\rangle$_{i}$ notation indicates the expectation value, which is calculated by summing over the index with the appropriate normalization. A PPP value of 1 indicates perfect predictability with no divergence in the ensemble simulations. PPP values of zero indicate no predictability with the variance of the ensemble simulations being equivalent to that from internal variability. PPP values are computed for the different ensemble prediction sets allowing us to evaluate how predictability changes with the changing sea ice state from the late twentieth to midtwenty-first century.

For comparison, we also consider the intraensemble anomaly correlation coefficient (ACC) as a prediction skill metric (Hawkins et al. 2016; Collins 2002). Because of the perfect-model nature of our experiments, each ensemble member can be considered as the "truth," and the ACC values computed here measure the correlation of predicted anomalies within the ensemble taking each ensemble member in turn as the truth. It is computed as

$$
\mathrm{ACC}=\frac{\left\langle\left(x_{i j}-\mu_{j}\right)\left(x_{k j}-\mu_{j}\right)\right\rangle_{i, j, k \neq i}}{\left\langle\left(x_{i j}-\mu_{j}\right)^{2}\right\rangle_{i, j}},
$$

where $\mu_{j}$ is the climatological mean computed from the control run (the CESM-LE) at the time of the ensemble prediction. This measures the correlation of predicted values across the ensemble and provides a measure of forecast accuracy of the ensemble predictions relative to the forecast accuracy of climatology.

\section{Results}

\section{a. Diagnostic predictability metrics from the CESM-LE}

Previous work has used correlation analysis to show a summer-to-summer reemergence of Arctic ice extent anomalies. This is associated with long-lived ice thickness anomalies (Blanchard-Wrigglesworth et al. 2011) that are formed during the fall freeze-up and related to the previous summer ice area. These thickness anomalies can then survive the winter season and affect melt out during the following summer. Given this, it is useful to assess statistical properties of September ice area and its predictors within the CESM-LE simulations. With the large number of simulations, we can also assess how these properties change with time by analyzing the simulations for different time windows. This provides insight on potential changes in sea ice predictability that can occur with a changing climate. In the analysis shown below, we consider running-decadal windows of CESM-LE anomalies relative to the ensemble mean. This allows us to focus on the year-to-year variability in the 


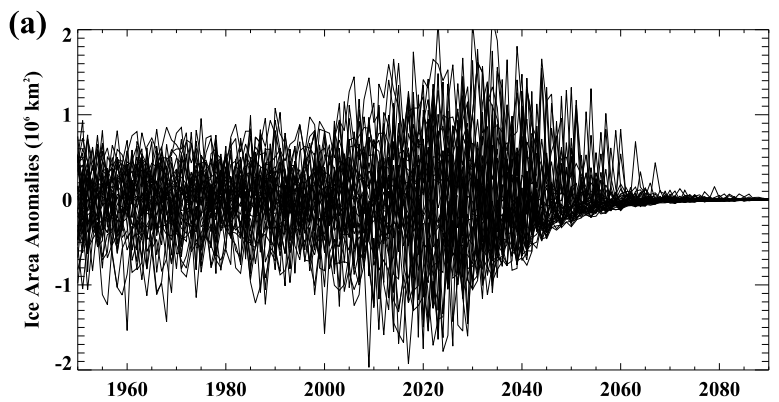

(b)

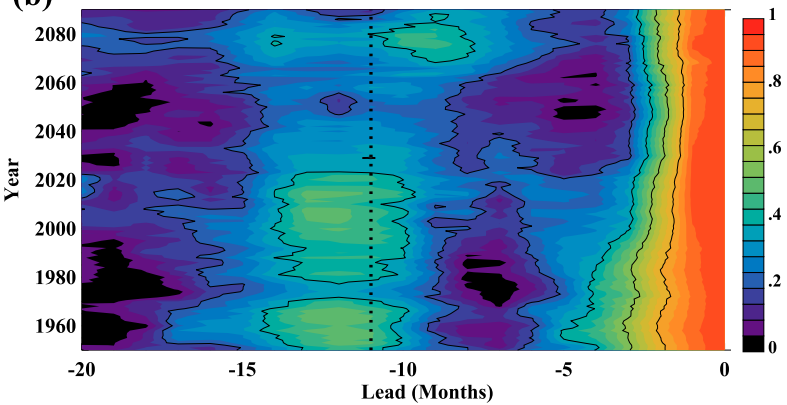

(c)

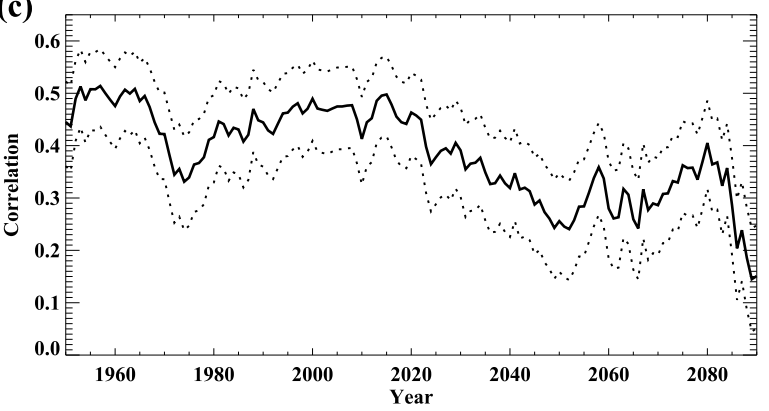

FIG. 3. (a) The time series of Arctic Ocean September ice area anomalies relative to the ensemble mean for each CESM-LE ensemble member. (b) The correlation of September Arctic Ocean ice area anomalies with ice area anomalies in previous months as a function of monthly lead time ( $x$ axis) and year of the twentieth or twenty-first century ( $y$ axis). The correlation is shown for 10-yr running windows of the anomalies relative to the ensemble mean. (c) The 1-yr lagged autocorrelation of September ice area anomalies for 10-yr running windows. The dotted lines indicate the $95 \%$ confidence interval. The time series in (c) is equivalent to the values shown in (b) at a lead of -11 months. This lead time is highlighted on (b) by the dotted line.

absence of the anthropogenically forced trend. We focus here primarily on the summer-to-summer reemergence characteristics and their influence on September ice area as opposed to shorter (a few month) time scales.

Figure 3 shows the time series of Arctic Ocean September ice area anomalies relative to the ensemble mean and the correlation of these anomalies in September with ice area anomalies in previous months. Similar to previous studies (Blanchard-Wrigglesworth et al. 2011; Cheng et al. 2016), the September ice area is (a)

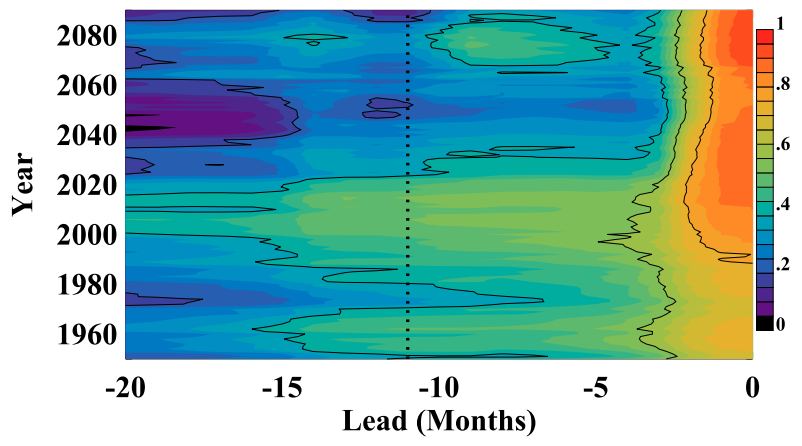

(b)

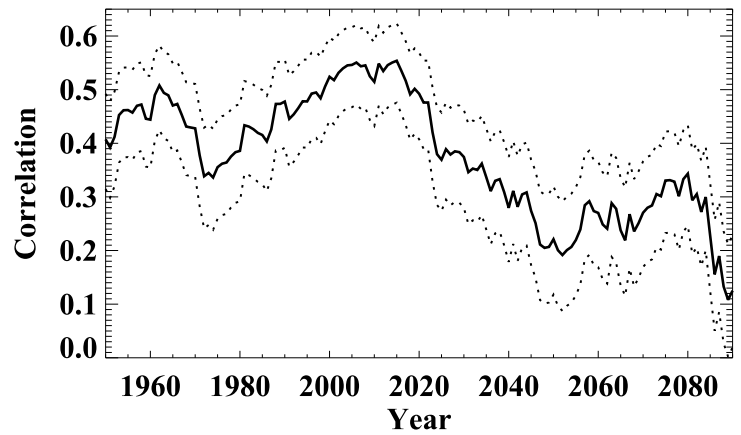

FIG. 4. (a) The correlation of Arctic Ocean September ice area anomalies with ice thickness anomalies in previous months as a function of ice thickness lead in months ( $x$ axis) and year of the twentieth or twenty-first century ( $y$ axis). (b) The correlation of September Arctic Ocean ice area anomalies with the previous September ice thickness anomalies. The dotted lines show the $95 \%$ confidence interval. The time series in (b) is equivalent to the values shown on (a) at a lead of -11 months. Values are shown for 10 -yr running windows of CESM-LE simulated anomalies from the ensemble mean.

highly correlated to conditions throughout the previous summer and has elevated correlation at a 1-yr lead indicating the summer-to-summer reemergence. The 1-yr lead correlation differs somewhat over the twentieth and twenty-first century and shows declining values after about 2020. This suggests that there is enhanced predictability at this 1 -yr lead time prior to 2020 although the differences are often not significant as indicated by the confidence interval (Fig. 3c).

As previously mentioned, the reemergence of ice area anomalies is related to long-lived ice thickness anomalies that can affect summer melt out. Correlation analysis (Fig. 4) reveals that, for Arctic basin averages, September ice area anomalies can be significantly related to ice thickness anomalies for over a year in advance, although this time scale differs for different decades through the twentieth and twenty-first centuries. Figure $4 \mathrm{~b}$ highlights these differences over time by showing the running correlations of September ice area 
(a)

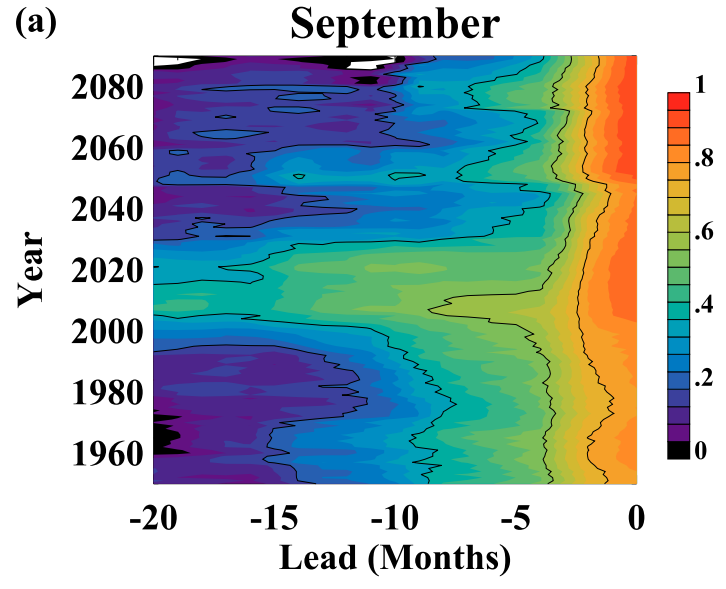

(c)

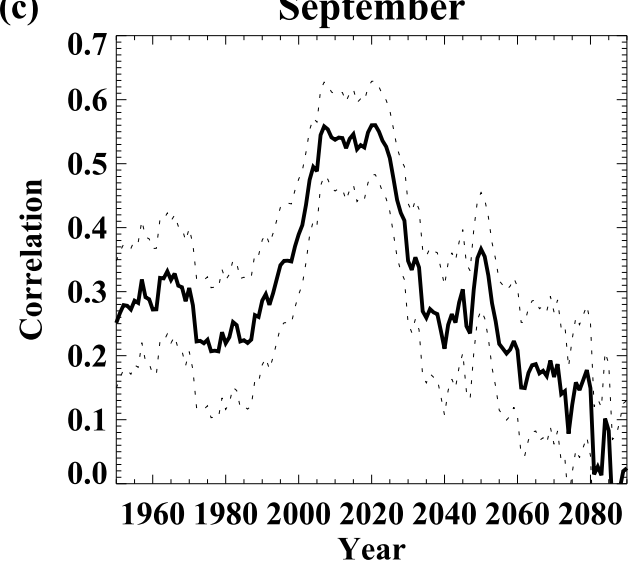

(b)

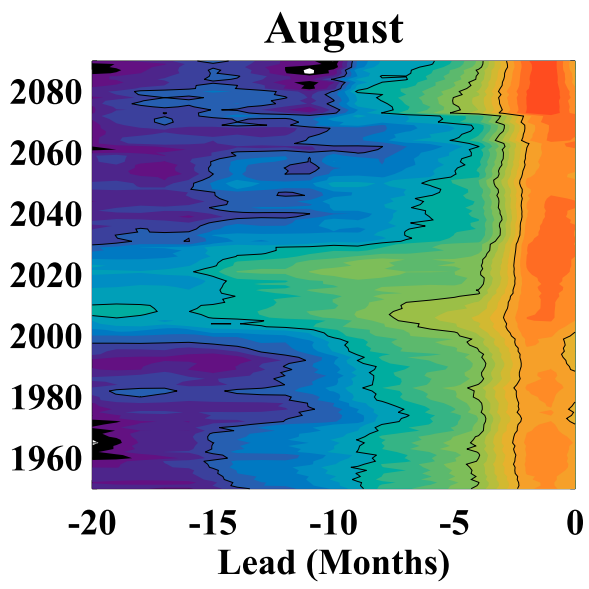

(d)

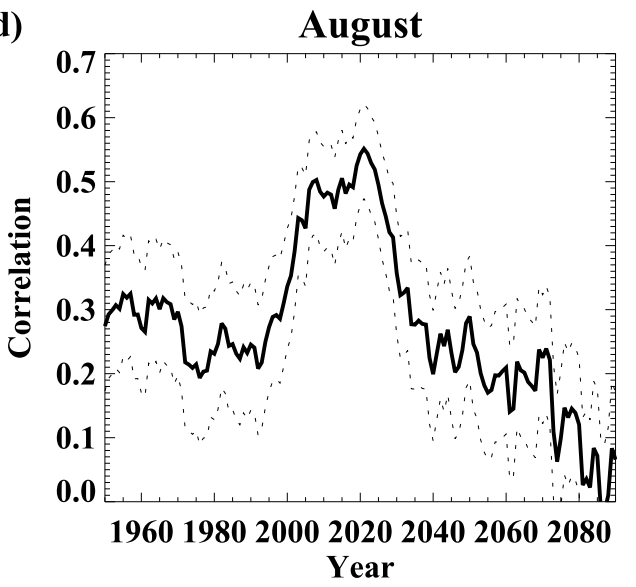

FIG. 5. The correlation of (a) September and (b) August Beaufort Sea ice area anomalies with ice thickness in prior months as a function of ice thickness lead in months ( $x$ axis) and year of the twentieth or twenty-first century $(y$ axis). (c) The time series of the correlation of September Beaufort Sea ice area anomalies with the previous September ice thickness [equivalent to the values at lead of -11 in (a)]. (d) The time series of the correlation of August Beaufort Sea ice area anomalies with the previous August ice thickness [equivalent to the values at lead of -11 in (b)]. The dashed lines in (c) and (d) indicate the $95 \%$ confidence interval.

with the prior September ice thickness. These correlations differ over time with a maximum correlation in the 2000-20 period, consistent with the maximum ice area autocorrelation. For the basin-scale anomalies shown here, the correlation coefficients after approximately 2030 fall outside the 2000-20 period confidence interval suggesting a significant change in predictability.

A case for changing predictability is more convincing when looking at regional variations. In particular, the suggestion of a peak in predictability is more obvious in the Beaufort Sea region (Fig. 5) where the correlations of late-summer ice area with previous thickness are significantly higher in the 2000-20 period relative to earlier or later time periods (Figs. 5c,d). Considering how these Beaufort Sea statistics change with the mean ice thickness (Fig. 6), there is the suggestion that with relatively thick mean sea ice in the late twentieth century (about 2.0-2.5 in September), the predictability is modest. As the September ice thins to between 0.5 and $1.5 \mathrm{~m}$ in the $2000-20$ period, the ice thickness is more highly correlated to the following September ice area, suggesting that predictability is increased. As the ice thins further after about 2020, the correlations again decrease. It is likely that some of the reduction in correlation for the thinnest ice regime (after 2020) is an artifact of the nearly total loss of September ice area that occurs starting in 2030 or so in some members. However, there are similar changing correlations between prior ice thickness and ice area in August as well (Fig. 5b) when the Arctic retains larger ice area. This suggests that some aspects of the declining role of ice thickness as a predictor of summer Arctic ice area may be a real signal and not solely an artifact of the loss of September sea ice. The Chukchi Sea also shows changing correlations that 


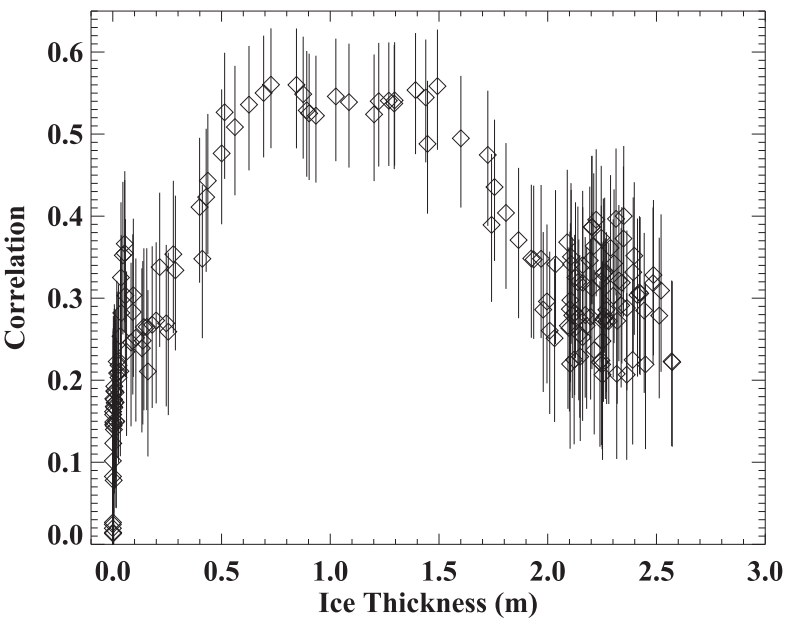

FIG. 6. The correlation of Beaufort Sea September ice area anomalies with the prior September ice thickness anomalies shown as a function of the ensemble mean September Beaufort Sea ice thickness. The vertical lines indicate the $95 \%$ confidence interval

are indicative of changing predictability characteristics (not shown), but not as strongly as the Beaufort Sea. We expect that this is because different factors drive ice thickness changes in different regions and will impact the relationship of winter ice thickness to the following summer melt.

This analysis of the CESM-LE suggests that Arctic sea ice predictability characteristics change in the changing climate. More specifically, correlation analysis suggests that the importance of ice thickness as a seasonal predictor of the following summer ice area is at first enhanced as sea ice thins in the early twenty-first century but then decreased as the ice thins further and approaches a seasonal ice pack. In the CESM-LE, there are indications that predictability of September sea ice area in the 2000-20 time period is enhanced relative to earlier or later time periods, particularly in the Beaufort Sea region. However, this differs regionally and the diagnostic analysis presented here only provides limited evidence of these changing predictability characteristics. Next, we turn to the initialized prediction ensemble experiments to further assess potential changes in predictability during the transient climate of the twentieth and twenty-first centuries.

\section{b. Initial-value predictability as assessed from the prediction ensemble}

As discussed in previous studies (Goosse et al. 2009; Holland et al. 2008), the internal variability of summer Arctic sea ice area increases in a warming climate. This is evident in the CESM-LE daily sea ice area variance at particular time slices, which generally increases from 1980 to 2030 with the timing of the annual variance maximum also shifting over the decades (Fig. 7). In contrast, the prediction ensemble ice area variance stays very similar for the 1980, 1990, 2000, and 2011 ensemble sets but then increases in 2021 and 2030. For the 1980 conditions, the prediction ensemble summer ice area variance is basically equivalent to internal variability as diagnosed from the CESM-LE. This indicates that January conditions provide little predictability for the following summer ice area. However, for later decades, the variance of the prediction ensemble is less than internal variability, suggesting that the January initialization provides predictability of the following summer ice area.

The PPP of gridded September sea ice concentration (Fig. 8) is consistent with the Arctic Ocean mean ice area analysis (Fig. 7). In particular, for regions with high ice area variability (which dominate the hemispheric mean), the PPP values are low in 1980, increase until reaching a maximum in 2010, and then decline thereafter. This is particularly true in the Beaufort Sea region. This is consistent with the diagnostic analysis of the CESM-LE and suggests that there is a "sweet spot" for summer Arctic ice area predictability for which the environmental conditions are optimal to allow skillful forecasts. Note that this predictability is quantified in the context of the changing internal variability of sea ice in contrast to previous work (Holland et al. 2011), which assessed predictability relative to a nonchanging measure of internal variability. The changing PPP values can represent both a change in the internal variability with time and a change in the ensemble forecast spread and as indicated by Fig. 7, different factors are more important for driving PPP changes in different decades. The results presented here indicate that initialized forecasts are more skillful in 2010 relative to the possible conditions that can occur for that time period as diagnosed from the CESM-LE. Because the internal variability does change with the mean sea ice state, we believe it is more appropriate to assess initial-value predictability relative to the possible states that can occur for a particular climate. For users of forecasts, this would appear to be a particularly relevant metric, because they are working in the context of the internal variability that can be expected for a particular time period. Notably, other prediction metrics, such as the anomaly correlation coefficient (ACC; e.g., Goddard et al. 2013) also indicate changing prediction skill with the changing climate (Fig. 9), with the largest values generally occurring for the 2011 ensemble set.

To understand what drives the change in predictability for different decades, we look to previous work and the diagnostic analysis discussed above that indicates that winter ice thickness anomalies can provide predictive capability for summer ice area. Assuming that 
(a)

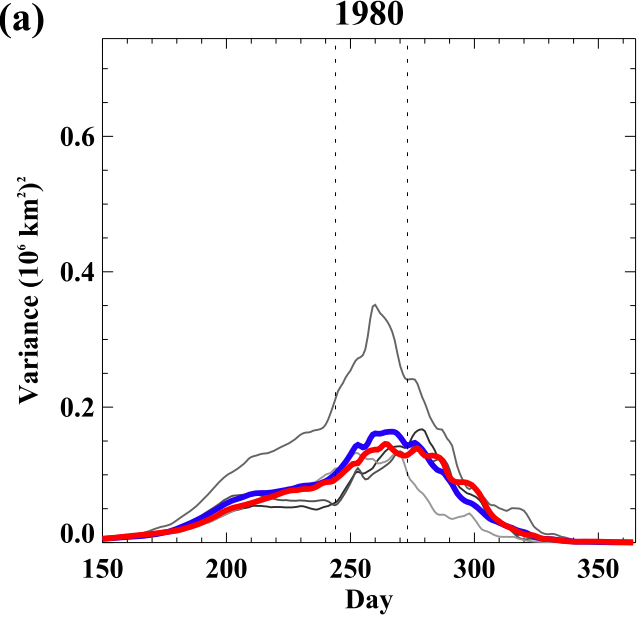

(c)

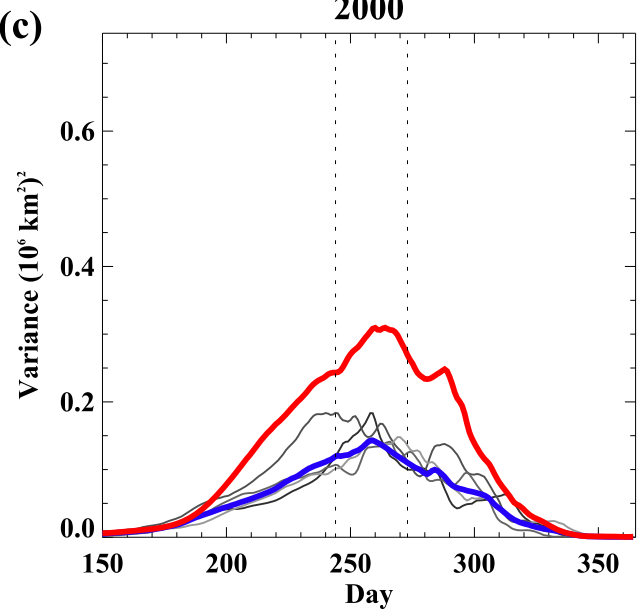

(e)

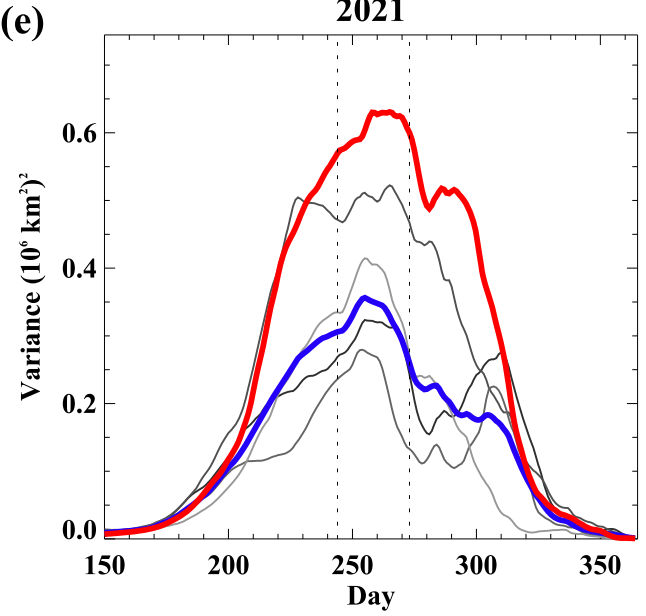

(b)
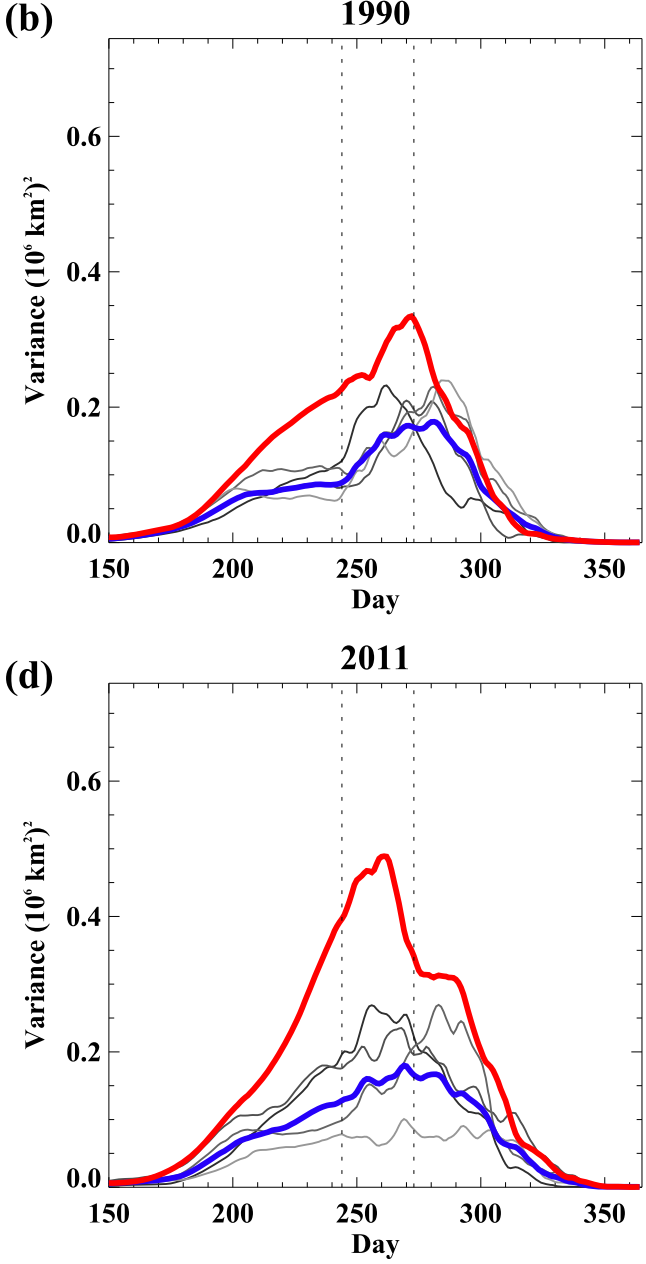

(f)

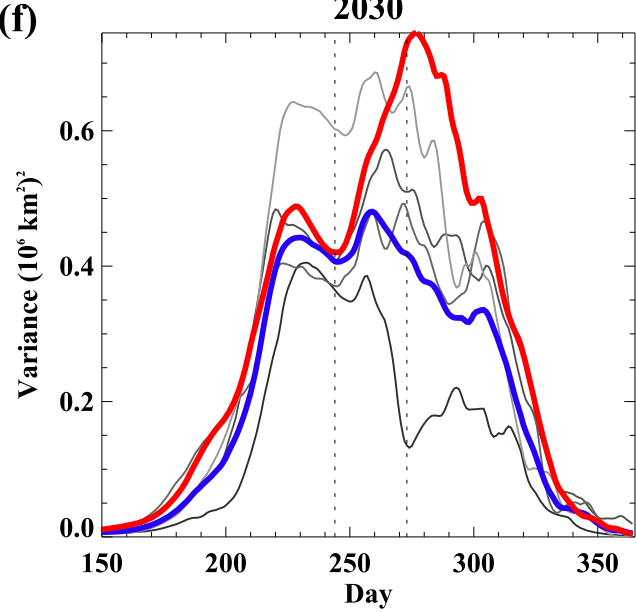

FIG. 7. The Arctic Ocean ice area daily variance from the 40 members of the CESM-LE at particular years (red curves) and from the initialized prediction ensemble (blue curves). Values are shown for different time periods of ensemble initialization: (a) 1980, (b) 1990, (c) 2000, (d) 2011, (e) 2021, and (f) 2030. Values from individual ensemble sets are shown in gray. The dotted vertical lines indicate the duration of September. 
(a) 1980

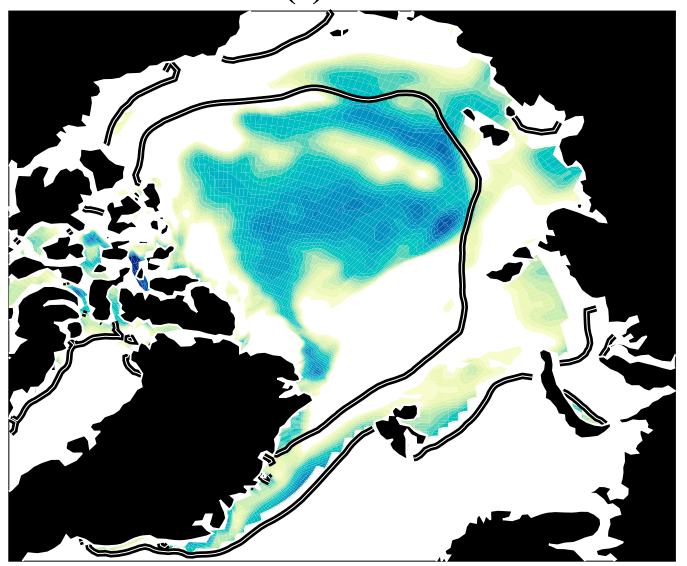

(c) 2000

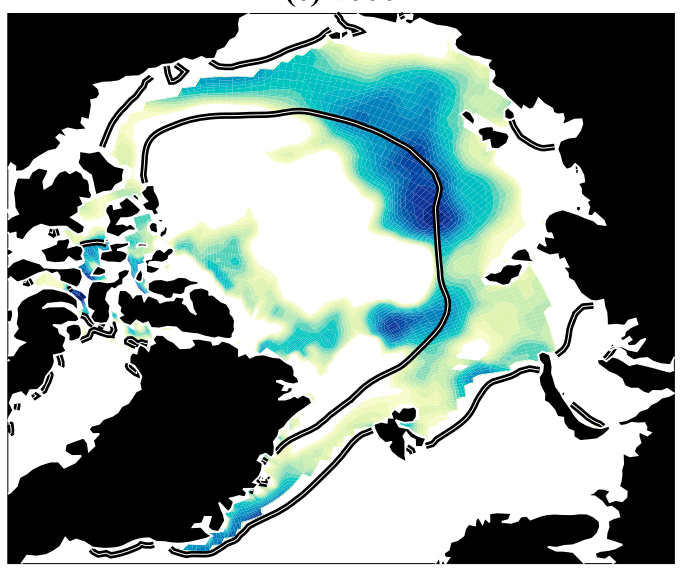

(e) 2021

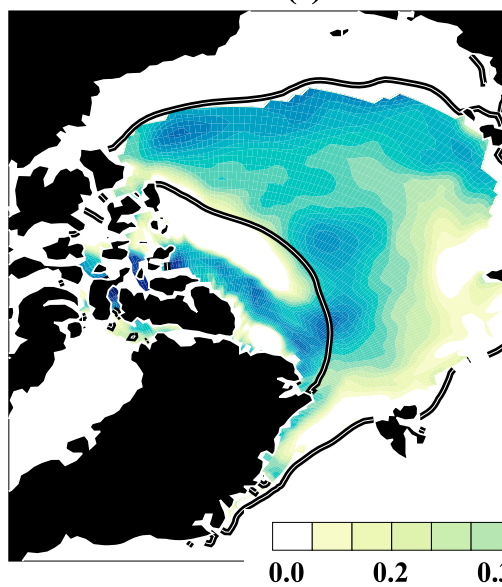

(b) 1990

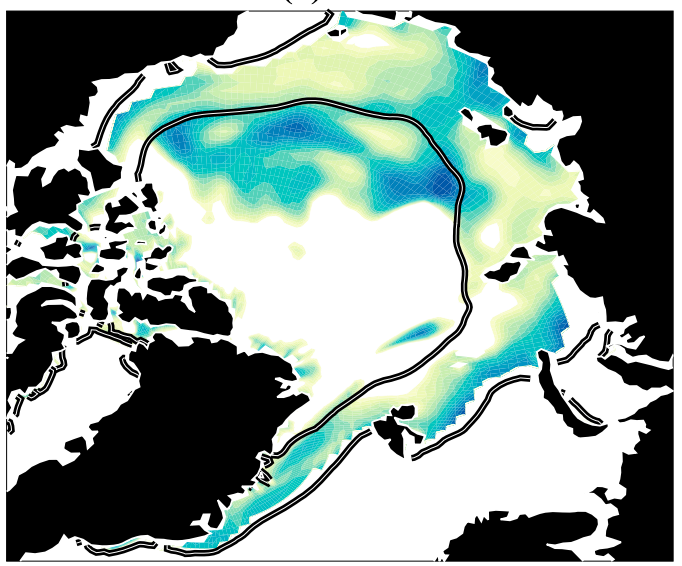

(d) 2011

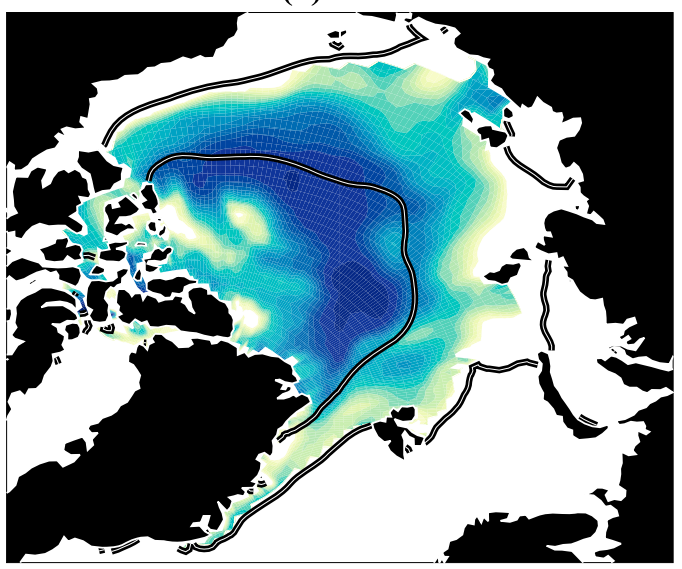

(f) 2030

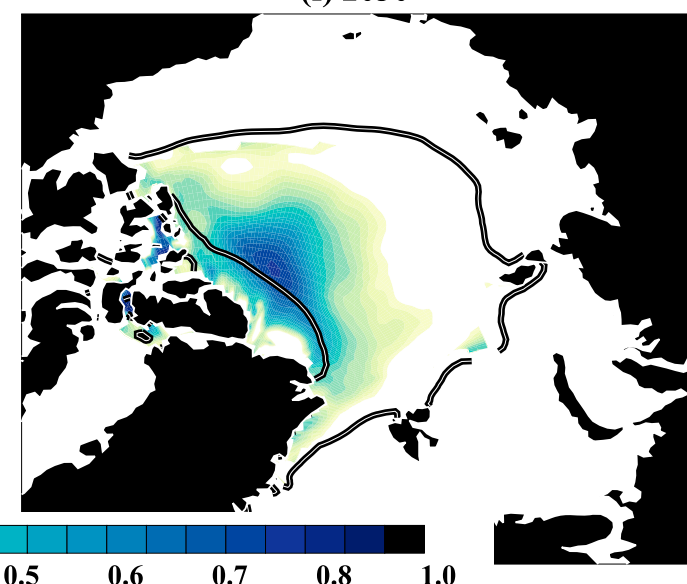

FIG. 8. The September ice concentration PPP values for the initialized ensemble prediction sets: (a) 1980, (b) 1990, (c) 2000, (d) 2011, (e) 2021 and (f) 2030. The thick contours indicate where the September ice concentration standard deviation of the CESM-LE is equal to 0.15 . The region within the thick contours indicates the area of high September ice concentration variance in the CESM-LE.

ice thickness is the primary predictor of summer ice area, the loss of predictability from initialized predictions can then be related to 1) the growth of ice thickness forecast errors from the initialized state (an "error growth factor") and 2) how those forecast errors in ice thickness affect the melt out of sea ice and the resulting summer ice area anomalies (a "thickness-sensitivity factor"). (For an operational forecast system, errors in the 

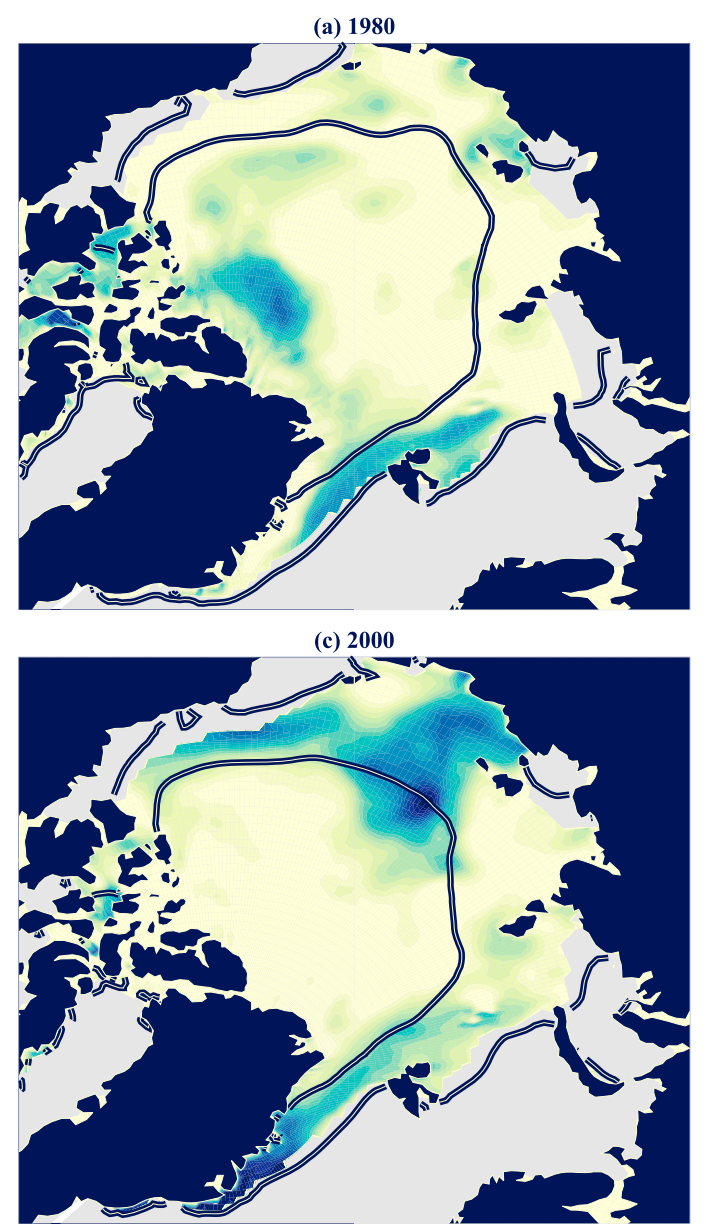

(e) 2021

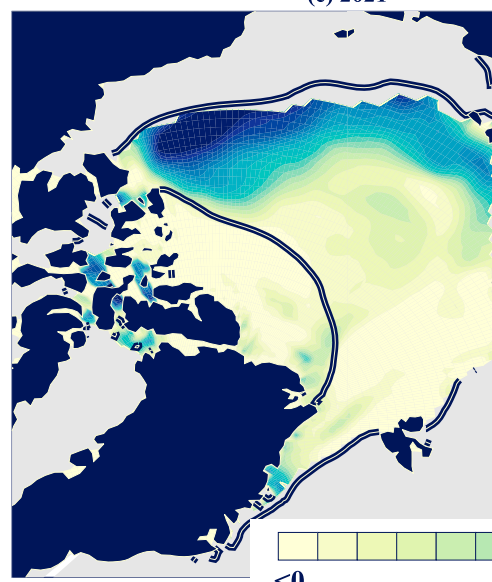

$<0$

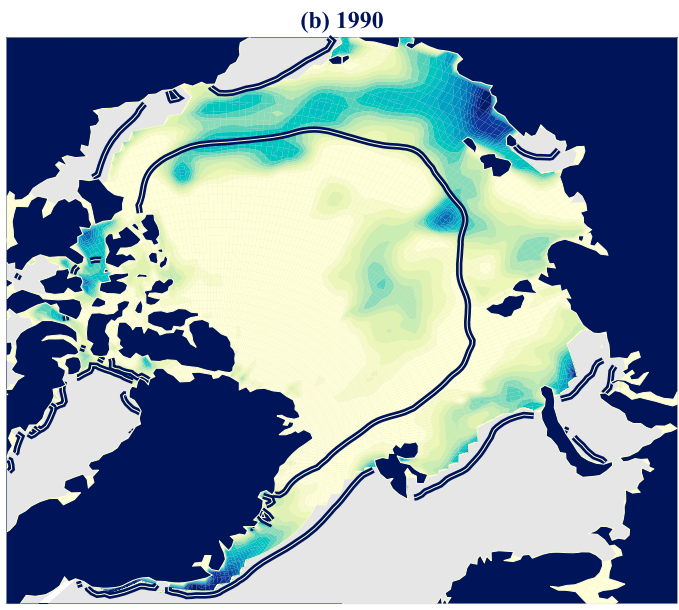

(d) 2011

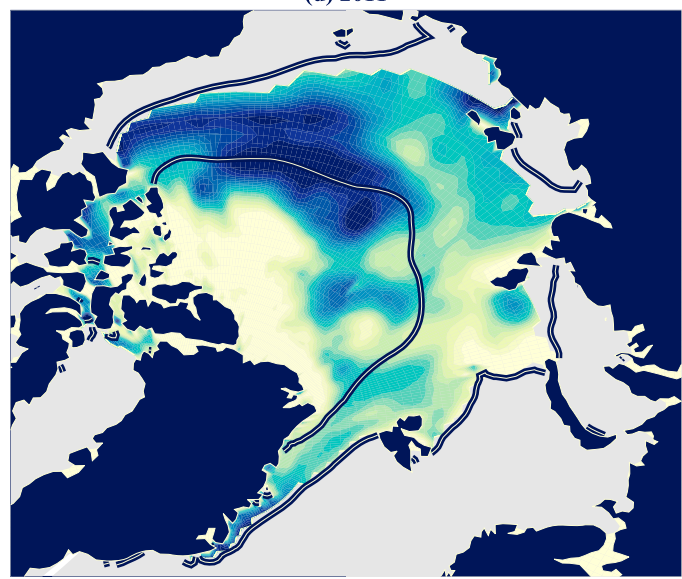

(f) 2030

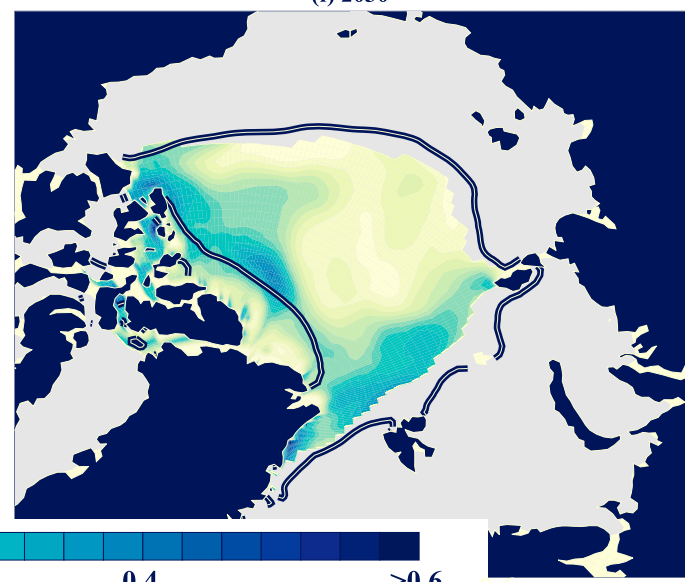

FIG. 9. The September ice concentration ACC values for the initialized ensemble prediction sets: (a) 1980, (b) 1990, (c) 2000, (d) 2011, (e) 2021, and (f) 2030. The thick contours are as in Fig. 8. Regions with less than 15\% ice concentration in the CESM-LE climatology for each year are shown in gray.

initial state and in the model itself will also of course play a role.) We quantify the growth of ice thickness forecast errors by assessing the ice thickness standard deviation (sigma) across the prediction ensemble members in July (in terms of both the spatial pattern and changes over time, qualitatively similar results are obtained if May or June anomalies used in this analysis). Note that the ensemble members have an identical initial 
thickness for each forecast ensemble set. However, the round-off level anomalies in the initialized air temperature will cause forecast errors throughout the system including in ice thickness. The influence of ice thickness anomalies on summer melt out is quantified using the regression of September ice concentration on July thickness anomalies (again similar qualitative results are obtained if the regression is computed using May or June thickness anomalies).

Figure 10 shows the standard deviation of the forecast July ice thickness for the different prediction ensemble sets. It indicates that the growth of ice thickness forecast errors is largest in the coastal regions. This is primarily associated with ice dynamics and ice transport variations that contribute to ice divergence or convergence anomalies. The ice thickness forecast error growth declines somewhat in the warmer climate of the 2020 and 2030 ensemble sets, particularly in the coastal regions. This is likely associated with the negative feedback between ice thickness and ice growth rate (Bitz and Roe 2004). Previous work has shown that this feedback is important for multidecadal changes in the CESM-LE (Petty et al. 2018) and it is also important for the growth of ice thickness forecast errors on seasonal time scales. Because the conduction of heat through sea ice is dependent on its thickness, ice growth increases for thinner ice. Notably, the strength of this feedback has a nonlinear dependence on ice thickness and is more effective for thin ice cover. This acts to damp ice thickness variability and limits error growth more strongly in a climate with thinner ice, resulting in low average ice thickness standard deviation for the Arctic Ocean in warmer decades (Fig. 11a). While these changes with the mean climate likely play some role, a more important factor is that the region of important ice thickness variations changes with the climate state. In just considering the region of high September ice area variability (shown by the region within the black contours on Fig. 10), it is clear that the coastal regions, which have high ice thickness forecast error growth, play a decreasingly important role for the September ice area variability in the warming climate. Instead these regions always completely melt out and so have no impact on the end of summer ice area variations. The July ice thickness anomalies important for September ice area change shift instead to the interior of the Arctic Ocean, where lower ice thickness forecast error growth is present (Fig. 10). Because of this, the error growth of ice thickness anomalies that are relevant for September ice area becomes progressively smaller for the ensemble sets in later decades (Fig. 11b; Table 1). On its own, this should act to enhance September ice concentration predictability in later decades.

However, as mentioned above, another important consideration for the September ice predictability is the role that early summer ice thickness anomalies have for the summer melt out. Figure 12 quantifies this through the regression of September ice concentration on July ice thickness anomalies in the CESM-LE. This indicates that these regression values are generally larger in the warming climate. As such, a similar magnitude July ice thickness anomaly will result in a larger September ice concentration anomaly in the later decades. This is associated with an increase in the variability of September ice concentration in the regions of increasing regression values as the climate warms. These regression values increase in part because a larger fraction of the Arctic basin has an ice thickness in July that is similar to the July-September total ice melt, which can reach $1-2 \mathrm{~m}$ but varies regionally and with time through the twentieth and twenty-first centuries. Because of this, anomalies in the July thickness are more likely to drive anomalies in melt out and hence September ice concentration over a large part of the Arctic basin. This is particularly true when averaging over the region of high September ice concentration variability for which the average regression value increases from $23.6 \% \mathrm{~m}^{-1}$ for the 1980 ensemble set to $53.9 \% \mathrm{~m}^{-1}$ for the 2030 ensemble set (Table 1).

To summarize, as the climate warms, the region of large September ice concentration variations moves from the shelf to the interior of the Arctic Ocean. For this region, ice thickness forecast error growth decreases in the warming climate. However, the influence of ice thickness errors on summertime melt out increases. These two factors have a competing influence on September ice concentration prediction skill. Because of this, there is a sweet spot for predictability when both of these factors are somewhat modest. In our model simulations, this occurs for the 2011 ensemble set. In the simulated 2011 time period, portions of the Beaufort and Chukchi Sea shelf regions no longer play a large role in September ice concentration anomalies because they almost always melt out. Instead, interior sea ice pack regions become important as September ice concentration anomalies extend into the Arctic basin. These are regions of more modest ice thickness forecast error growth and so overall, the important early summer ice thickness errors remain smaller than for earlier decades. These ice thickness forecast errors also have a more modest influence on summer melt out and resulting September ice concentration anomalies than in later decades. This combination of factors enhances predictability for the 2011 ensemble set relative to the other decades. This is consistent with the diagnostic analysis shown in section 3 a.

\section{c. Comparison with previous work}

Two previous studies have assessed changes in sea ice predictability over the twentieth and twenty-first 
(a) 1980

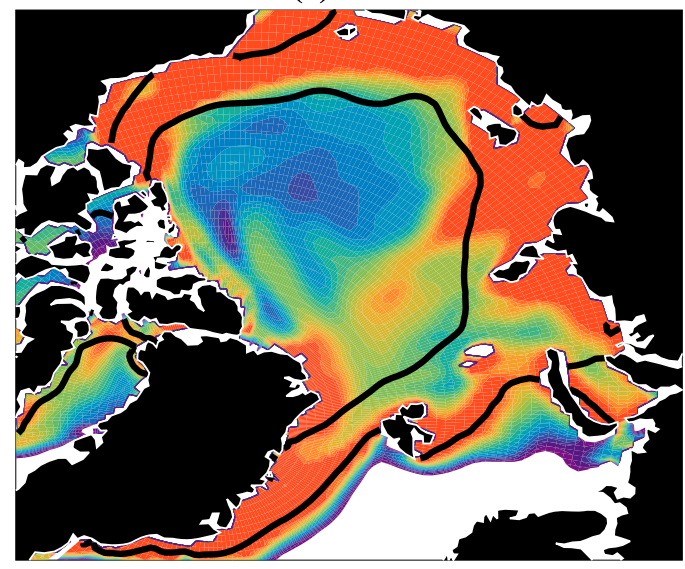

(c) 2000

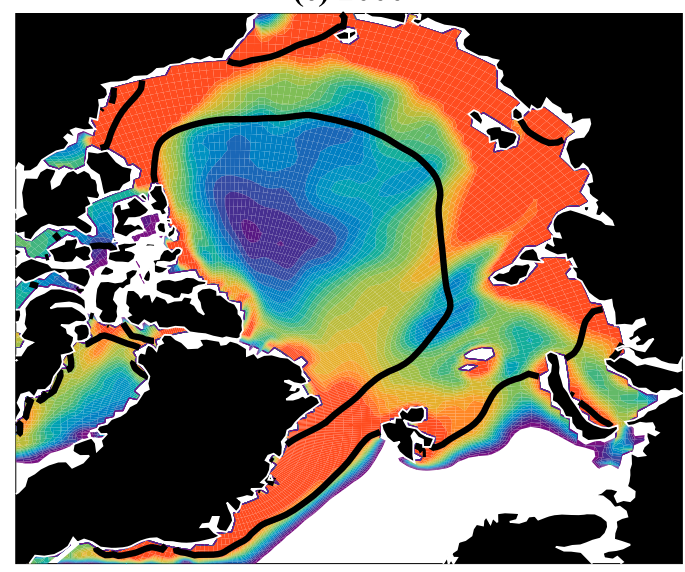

(e) 2021

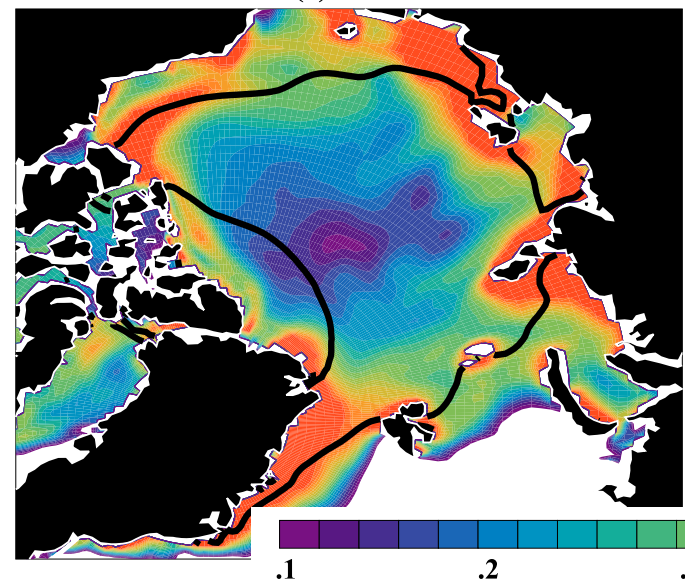

(b) 1990

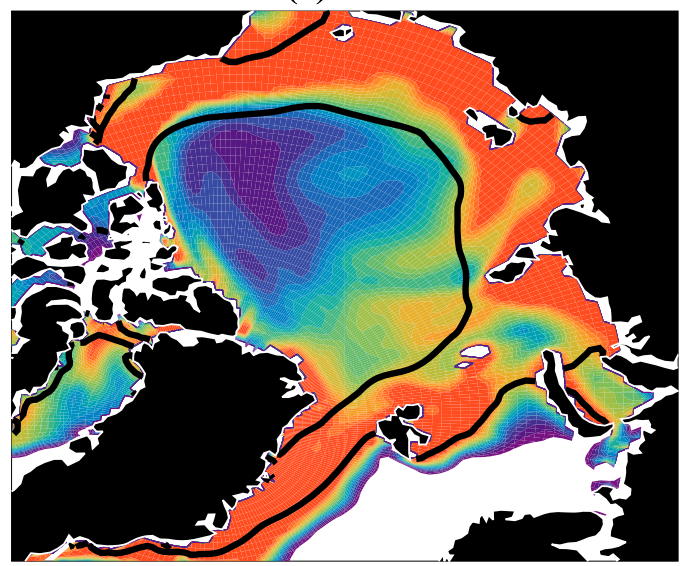

(d) 2011

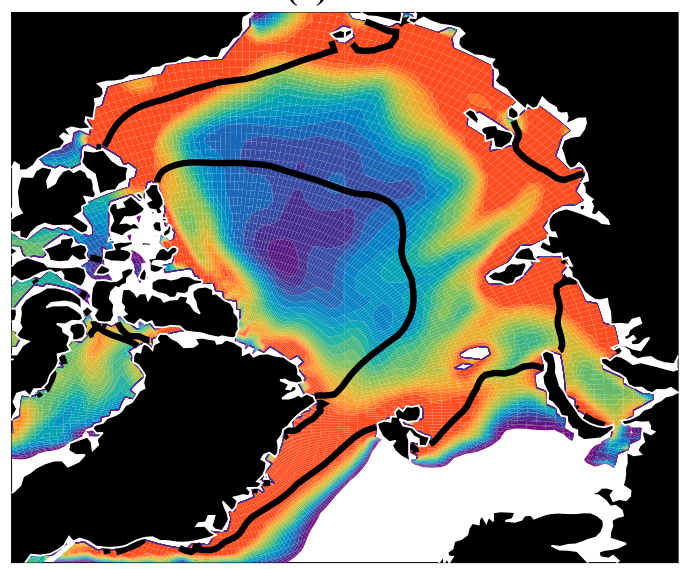

(f) 2030

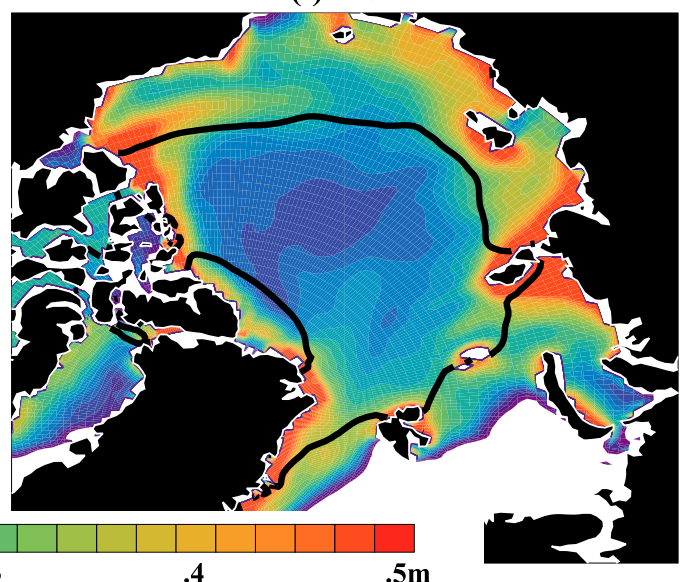

FIG. 10. The standard deviation of ice thickness across the ensemble prediction simulations in July in meters for (a) 1980, (b) 1990, (c) 2000, (d) 2011, (e) 2021 and (f) 2030. The thick contours are as in Fig. 8.

century (Holland et al. 2011; Cheng et al. 2016). Holland et al. (2011) used perfect-model prediction ensemble simulations from the Community Climate System Model 3 (CCSM3; Collins et al. 2006) and compared runs initialized in 1970, 2016 and 2017. This work found that summer ice area is more predictable in a thick (late twentieth century) sea ice regime. This is in apparent contrast to the results presented here. Much of this discrepancy likely lies in the climate regime that is used to characterize the internal variability of sea ice. The 
(a)

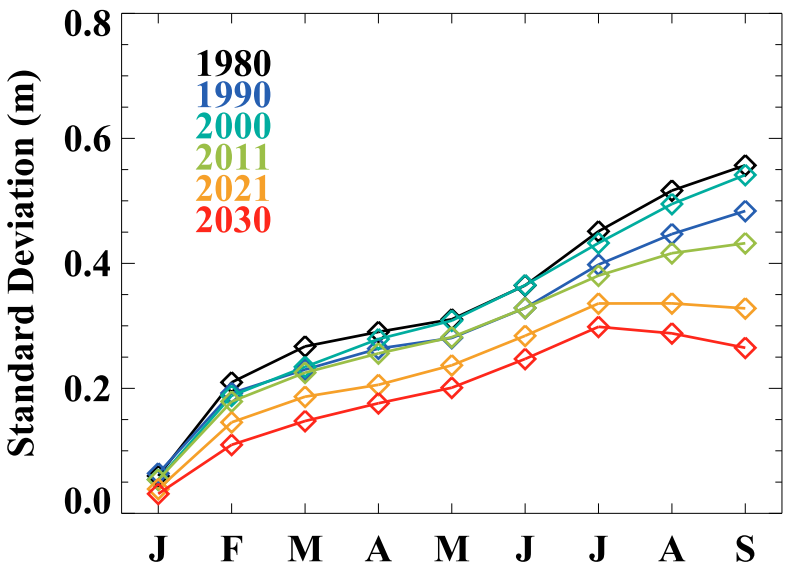

(b)

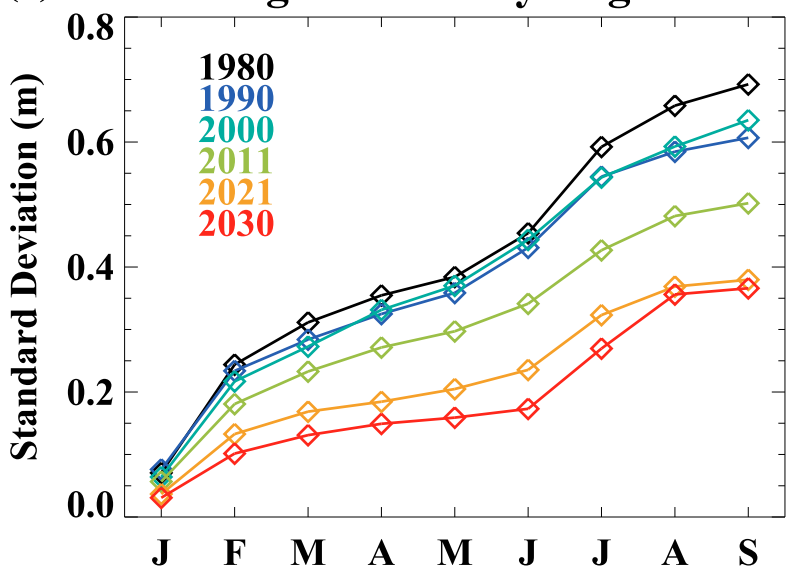

FIG. 11. The standard deviation across the ensemble prediction simulations of ice thickness averaged for (a) an Arctic Ocean region and (b) the region of high September ice concentration variability, defined as the region with September ice concentration standard deviation of greater than 0.15 .

internal variability of summer ice concentration increases in a warming climate (Goosse et al. 2009; Holland et al. 2008; Mioduszewski et al. 2019) and so comparing predictability for different time periods with reference to a fixed characterization of the climate versus a changing characterization of the climate will affect the results. Holland et al. (2011) used a fixed characterization of the climate state (from a present day control simulation) in contrast to the changing characterization that we obtain from the CESM-LE. We believe that it is preferable to assess predictability in the context of the possible conditions that can occur in the particular climate state of interest and this is possible using the large number of ensemble members from the transient CESMLE simulations. The correlation metrics are consistent
TABLE 1. Factors driving summer ice area prediction errors for the different ensemble sets: an ice thickness error growth factor and a thickness sensitivity factor. The ice thickness error growth factor is computed as the standard deviation of July ice thickness over the ensemble simulations, and the thickness sensitivity factor is computed as the regression of September ice concentration on July ice thickness. The 1-sigma uncertainty estimates for the thickness sensitivity factor regression coefficients are shown in parentheses. Values are averaged over the region of high September ice area variability designated by the region with a September ice concentration standard deviation of greater than 0.15 .

\begin{tabular}{ccc}
\hline $\begin{array}{c}\text { Ensemble } \\
\text { set }\end{array}$ & $\begin{array}{c}\text { July ice thickness error } \\
\text { growth factor }(\mathrm{m})\end{array}$ & $\begin{array}{c}\text { Thickness sensitivity } \\
\text { factor }\left(\% \mathrm{~m}^{-1}\right)\end{array}$ \\
\hline 1980 & 0.59 & $23.6(2.87)$ \\
1990 & 0.54 & $24.6(2.83)$ \\
2000 & 0.54 & $24.8(3.00)$ \\
2011 & 0.42 & $29.2(3.46)$ \\
2021 & 0.32 & $41.3(4.51)$ \\
2030 & 0.27 & $53.9(5.75)$ \\
\hline
\end{tabular}

with this since their squared value, or $R^{2}$, measures the fraction of the variance explained by a linear relationship and the magnitude of that variance will change in the different climate states.

Cheng et al. (2016) used the same CESM-LE simulations assessed here to diagnose changing predictability characteristics of ice area. In particular, they computed lagged correlations of the ice area anomalies from the ensemble mean for pan-Arctic, Chukchi Sea, and Beaufort Sea regions using 35-yr running windows for the 1920-2080 period. From this, they found that the summer to summer autocorrelation of ice area weakens in the latter half of the twenty-first century as the climate warms, which is evidence of decreasing predictability. This is consistent with the lower autocorrelation values in the late twenty-first century shown in Figs. 3 and 4 for the Arctic Ocean and shown in Fig. 5 for the Beaufort Sea. However, Cheng et al. (2016) find little evidence for increased autocorrelation in the 2000-20 period, which in our analysis is particularly significant in the Beaufort Sea (Fig. 5). We expect that this discrepancy is due to the time period used for analysis. The increase in predictability that we find is a decadal-scale phenomenon and is detectable because of the 10 -yr periods that we analyze. The longer time scales (of 35-yr running windows) assessed in Cheng et al. (2016) obscure these decadal-scale contrasts in predictability and instead focus on the longer-time-scale behavior.

\section{Summary and conclusions}

The Arctic is undergoing rapid change, and seasonally ice free conditions are projected to occur within this century (e.g., Jahn et al. 2016). Sea ice decline and enhanced marine 
(a) 1980

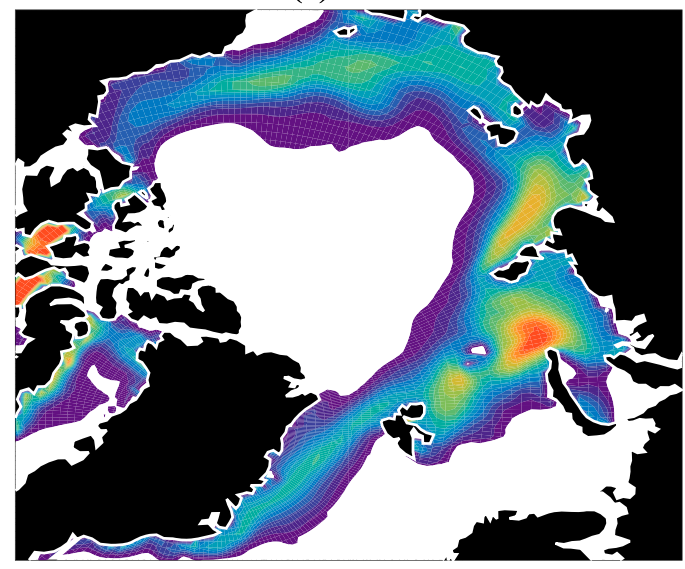

(c) 2000

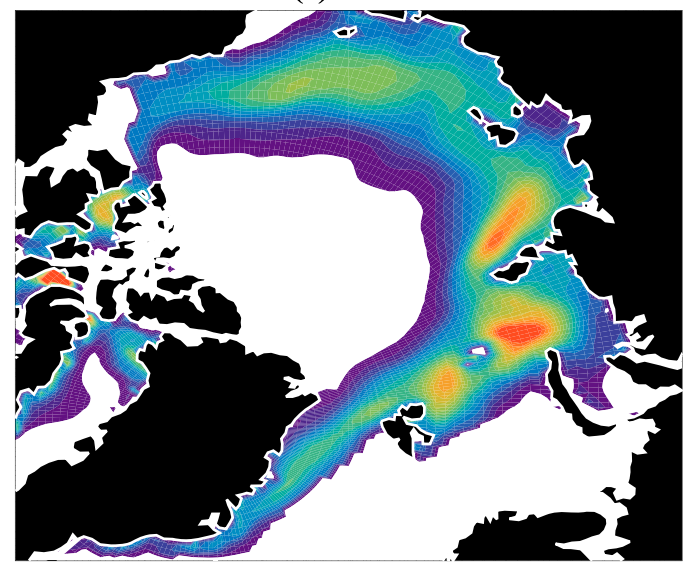

(e) 2021

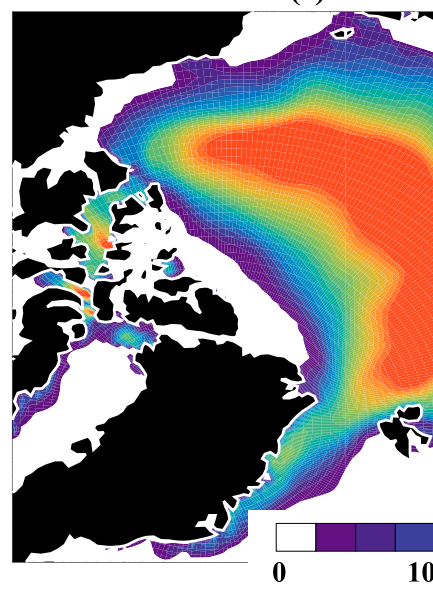

(b) 1990

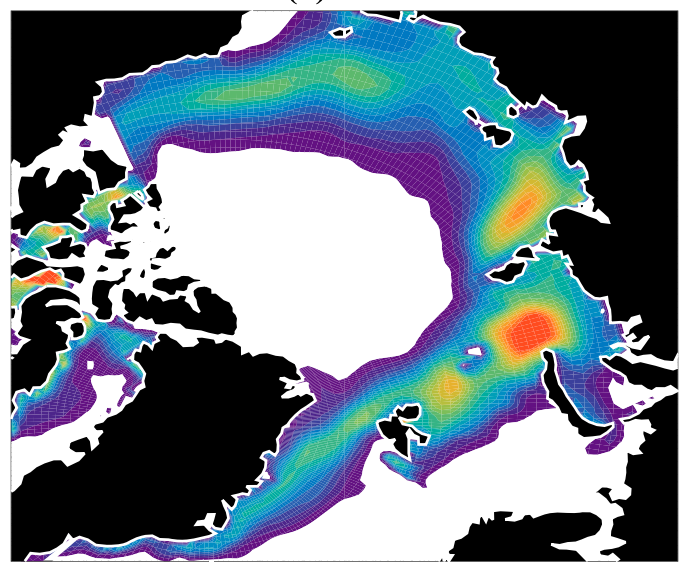

(d) 2011

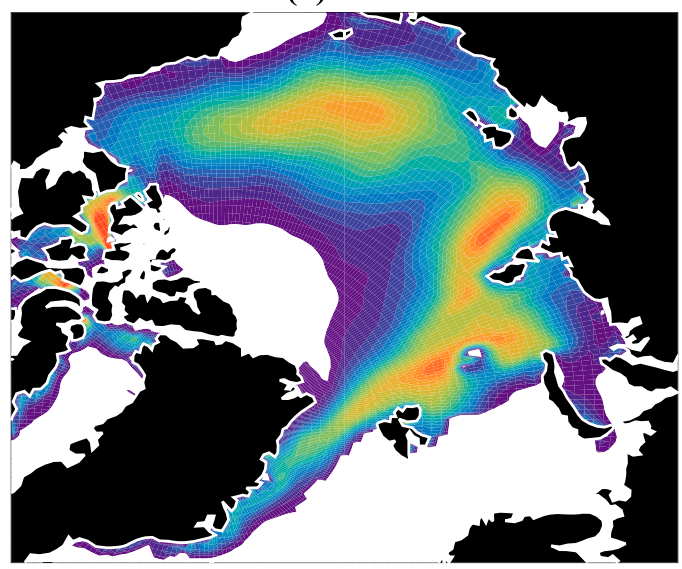

(f) 2030

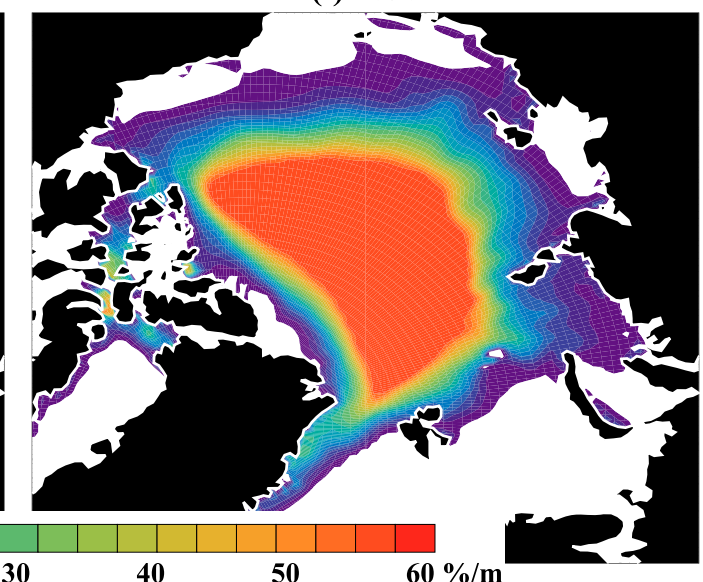

FIG. 12. The regression of September ice concentration on the preceding July ice thickness in percent per meter from the CESM-LE for (a) 1980, (b) 1990, (c) 2000, (d) 2011, (e) 2021, and (f) 2030. Regressions are computed using all members from the CESM-LE for the three years that are centered on the year of interest.

access have led to increased activity within the Arctic Ocean, with an associated need for reliable predictions of Arctic sea ice variations. While a number of previous studies have assessed the predictability of Arctic sea ice (e.g.,
Blanchard-Wrigglesworth et al. 2011; Holland et al.,2011; Day et al. 2016; Tietsche et al. 2014), limited work has been done to understand how the changing mean sea ice conditions may impact that seasonal predictability over time. 
Here we have assessed decadal-scale changes in summer Arctic sea ice predictability using both diagnostic analysis of a large ensemble of simulations (the CESMLE) for the twentieth and twenty-first centuries and using perfect-model experiments that are initialized at decadal intervals from 1980 to 2030 . Over this period from the late-twentieth to the mid-twenty-first century, the sea ice undergoes large ice area loss (particularly in summer) and considerable sea ice thinning. This has the potential to affect predictability characteristics of the sea ice.

From a diagnostic analysis of the CESM-LE, we find evidence that predictability characteristics do indeed change over the late twentieth and twenty-first century. As found in previous work, the CESM-LE exhibits significant correlations of the September Arctic Ocean ice area with both ice area and ice thickness in the summer of the previous year. However, the magnitude of this correlation changes over decadal intervals and appears to be enhanced in the period from 2000 to 2020. This is particularly obvious in the Beaufort Sea region, which has relatively high correlations of late-summer ice area with ice thickness in the prior 15 months during the period from 2000 to 2020.

Results from our perfect-model experiments are generally consistent with this diagnostic predictability analysis and indicate that for predictions initialized on 1 January, the summer Arctic ice area has elevated predictability in a 2011 ensemble set. This is apparent in both the Arctic total ice area and the gridded values of ice concentration. To understand the factors driving this change in predictability, we have assessed two sources of errors that can result in late-summer ice area anomalies in our initialized perfect-model forecasts. This includes 1) the growth of ice thickness forecast errors from initialization until the summer and 2) the influence of summer ice thickness anomalies on summer melt out. The ice thickness error growth is largest in coastal regions. This declines in a warming climate. Additionally, as the climate warms, coastal regions begin to melt out completely and September ice concentration anomalies shift to the interior of the Arctic Ocean. These interior pack regions have lower ice thickness forecast error growth in part because the interior regions are less subject to growth in errors associated with ice dynamics. As a result, the growth of important ice thickness errors is smaller in the warming climate, which would lead to enhanced predictability.

However, our results also indicate that early summer ice thickness forecast errors have a larger impact on summer melt out in the warming climate. This results in part from larger areas of the ice pack being near the average melt out thickness and thus smaller forecast errors in ice thickness have a larger impact on the summer open water formation. This contributes to a loss of sea ice predictability that is larger in the warming climate. This counteracts the gain in predictability associated with the decrease in the ice thickness forecast error growth in a warming climate.

The net effect of these two factors is that there is a sweet spot for predictability in the intermediate time frame. In our model simulations, this occurs for ensemble simulations initialized in 2011 and is particularly prominent in the Beaufort Sea region. These changing temporal and regional predictability characteristics have implications for the optimal initialization of operational forecast systems. In particular, it suggests that the ice thickness initialization needs for skillful sea ice forecasts are climate dependent. Because of the importance of ice thickness forecast errors for summer ice area predictability, initializing operational forecasts at shorter lead times should improve summer ice area forecast skill as indicated in previous work (e.g., Day et al. 2014b). However, our results suggest that the characteristics of this improvement will depend on the mean climate state.

Given that there are large discrepancies across models in their simulated ice concentration and thickness, we expect that the time frame for optimal predictability and the regional character of the changing predictability will likely differ across models. As shown in Labe et al. (2018), the CESM-LE sea ice thickness is biased a bit thick relative to the Pan-Arctic Ice Ocean Modeling and Assimilation System (PIOMAS) observationally based estimates (Zhang and Rothrock, 2003; Schweiger et al. 2011). Given the thickness dependence of the changing predictability, this suggests that the timeframe for optimal seasonal predictability may occur somewhat later in the model system than in reality. However, given that the CESM-LE has an overall very reasonable mean sea ice state, our results do suggest that the optimal seasonal predictability of September Arctic sea ice area has recently occurred and that this predictability will degrade into the future. Our metrics of the factors driving ice predictability loss provide a useful means to compare across models with different mean climate states.

Acknowledgments. Support was provided by the NOAA Climate Program Office under Climate Variability and Predictability Program Grants NA15OAR4310167 and NA15OAR4310166. Computing resources for the CESM-LE simulations were provided by the NSFsponsored Climate Simulation Laboratory at NCAR's Computational and Information Systems Laboratory. The CESM-LE simulations are publicly available from NCAR's Climate Data Gateway. This material is based upon work supported by the National Center for Atmospheric Research, which is a major facility sponsored 
by the National Science Foundation under Cooperative Agreement 1852977. We also thank three anonymous reviewers for their comments that led to improvements in the paper.

\section{REFERENCES}

Bitz, C. M., and G. H. Roe, 2004: A mechanism for the high rate of sea ice thinning in the Arctic Ocean. J. Climate, 17, 3623-3632, https://oi.org/10.1175/1520-0442(2004)017<3623:AMFTHR >2.0.CO;2.

Blanchard-Wrigglesworth, E., K. C. Armour, C. M. Bitz, and E. DeWeaver, 2011: Persistence and inherent predictability of Arctic sea ice in a GCM ensemble and observations. J. Climate, 24, 231-250, https://doi.org/10.1175/ 2010JCLI3775.1.

Bushuk, M., R. Msadek, M. Winton, G. Vecchi, X. Yang, A. Rosati, and R. Gudgel, 2019: Regional Arctic sea-ice prediction: Potential versus operational seasonal forecast skill. Climate Dyn., 52, 2721-2743, https://doi.org/10.1007/s00382-018-4288-y.

Cheng, W., E. Blanchard-Wrigglesworth, C. M. Bitz, C. Ladd, and P. Stabeno, 2016: Diagnostic sea ice predictability in the panArctic and U.S. Arctic regional seas. Geophys. Res. Lett., 43, 11 688-11 696, https://doi.org/10.1002/2016GL070735.

Chevallier, M., D. Salas y Mélia, A. Voldoire, M. Déqué, and G. Garric, 2013: Seasonal forecasts of the pan-Arctic sea ice extent using a GCM-based seasonal prediction system. J. Climate, 26, 6092-6104, https://doi.org/10.1175/JCLI-D-1200612.1.

Collins, M., 2002: Climate predictability on interannual to decadal time scales: The initial value problem. Climate Dyn., 19, 671692, https://doi.org/10.1007/s00382-002-0254-8.

— dictability in the North Atlantic:A multimodel-ensemble study. J. Climate, 19, 1195-1202, https://doi.org/10.1175/JCLI3654.1.

Collow, T. W., W. Wang, A. Kumar, and J. Zhang, 2015: Improving Arctic sea ice prediction using PIOMAS initial sea ice thickness in a coupled ocean-atmosphere model. Mon. Wea. Rev., 143, 4618-4630, https://doi.org/10.1175/MWR-D-15-0097.1.

Day, J. J., E. Hawkins, and S. Tietsche, 2014a: Will Arctic sea ice thickness initialization improve seasonal forecast skill? Geophys. Res. Lett., 41, 7566-7575, https://doi.org/10.1002/ 2014GL061694.

— S. Tietsche, and E. Hawkins, 2014b: Pan-Arctic and regional sea ice predictability: Initialization month dependence. J. Climate, 27, 4371-4390, https://doi.org/10.1175/JCLI-D-1300614.1.

- and Coauthors, 2016: The Arctic Predictability and Prediction on Seasonal-to-Interannual Timescales (APPOSITE) data set version 1. Geosci. Model Dev., 9, 2255-2270, https:// doi.org/10.5194/gmd-9-2255-2016.

Dirkson, A., W. J. Merryfield, and A. Monahan, 2017: Impacts of sea ice thickness initialization on seasonal Arctic sea ice predictions. J. Climate, 30, 1001-1017, https://doi.org/10.1175/ JCLI-D-16-0437.1.

Drobot, S. D., J. A. Maslanik, and C. Fowler, 2006: A longrange forecast of Arctic summer sea ice minimum extent. Geophys. Res. Lett., 33, L10501, https://doi.org/10.1029/ 2006GL026216.

Fetterer, F., K. Knowles, W. Meier, M. Savoie, and A. K. Windnagel, 2017: Sea ice index, version 3 (updated daily). National Snow and Ice Data Center, Boulder, CO, accessed 28 September 2017, https://doi.org/10.7265/N5K072F8.
Goddard, L., and Coauthors, 2013: A verification framework for interannual-to-decadal predictions experiments. Climate Dyn., 40, 245-272, https://doi.org/10.1007/s00382-012-1481-2.

Goosse, H., O. Arzel, C. M. Bitz, A. de Montety, and M. Vancoppenolle, 2009: Increased variability of the Arctic summer ice extent in a warmer climate. Geophys. Res. Lett., 36, L23702, https://doi.org/10.1029/2009GL040546.

Guemas, V., and Coauthors, 2016: A review on Arctic sea-ice predictability and prediction on seasonal to decadal timescales. Quart. J. Roy. Meteor. Soc., 142, 546-561, https:// doi.org/10.1002/qj.2401.

Hawkins, E., S. Tietsche, J. J. Day, N. Melia, K. Haines, and S. Keeley, 2016: Aspects of designing and evaluating seasonalto-interannual Arctic sea-ice prediction systems. Quart. J. Roy. Meteor. Soc., 142, 672-683, https://doi.org/10.1002/ qj.2643.

Holland, M. M., and J. Stroeve, 2011: Changing seasonal sea ice predictor relationships in a changing Arctic climate. Geophys. Res. Lett., 38, L18501, https://doi.org/10.1029/2011GL049303.

_ surface shortwave heating and albedo change in coupled climate models. Philos. Trans. Roy. Soc. London, A373, 2045, https://doi.org/10.1098/rsta.2014.0162.

— C. M. Bitz, B. Tremblay, and D. A. Bailey, 2008: The role of natural versus forced change in future rapid summer Arctic ice loss. Arctic Sea Ice Decline: Observations, Projections, Mechanisms, and Implications, Geophys. Monogr., Vol. 180, Amer. Geophys. Res., 133-150.

- D. A. Bailey, and S. Vavrus, 2011: Inherent sea ice predictability in the rapidly changing Arctic environment of the Community Climate System Model, version 3. Climate Dyn., 36, 1239-1253, https://doi.org/10.1007/s00382-010-0792-4.

Hurrell, J. W., and Coauthors, 2013: The Community Earth System Model: A framework for collaborative research. Bull. Amer. Meteor. Soc., 94, 1339-1360, https://doi.org/10.1175/BAMS-D12-00121.1.

Jahn, A., J. E. Kay, M. M. Holland, and D. M. Hall, 2016: How predictable is the timing of a summer ice-free Arctic? Geophys. Res. Lett., 43, 9113-9120, https://doi.org/10.1002/ 2016 GL070067.

Kay, J. E., and Coauthors, 2015: The Community Earth System Model (CESM) Large Ensemble Project: A community resource for studying climate change in the presence of internal climate variability. Bull. Amer. Meteor. Soc., 96, 1333-1349, https://doi.org/10.1175/BAMS-D-13-00255.1.

Labe, Z., G. Magnusdottir, and H. Stern, 2018: Variability of Arctic sea ice thickness using PIOMAS and the CESM Large Ensemble. J. Climate, 31, 3233-3247, https://doi.org/10.1175/ JCLI-D-17-0436.1.

Lamarque, J. F., G. P. Kyle, M. Meinshausen, K. Riahi, S. J. Smith, D. P. van Vuuren, A. J. Conley, and F. Vitt, 2011: Global and regional evolution of short-lived radiatively-active gases and aerosols in the Representative Concentration Pathways. Climatic Change, 109, 191-212, https://doi.org/10.1007/s10584011-0155-0.

Massonnet, F., M. Vancoppenolle, H. Goosse, D. Docquier, T. Fichefet, and E. Blanchard-Wrigglesworth, 2018: Arctic sea-ice change tied to its mean state through thermodynamic processes. Nat. Climate Change, 8, 599-603, https://doi.org// s41558-018-0204-z.

Meinshausen, M., and Coauthors, 2011: The RCP greenhouse gas concentrations and their extension from 1765 to 2300 . Climatic Change, 109, 213, https://doi.org/10.1007/s10584-011-0156-z. 
Mioduszewski, J. R., S. Vavrus, M. Wang, M. Holland, and L. Landrum, 2019: Past and future interannual variability of Arctic sea ice in coupled climate models. Cryosphere, 13,113124, https://doi.org/10.5194/tc-13-113-2019.

Msadek, R., G. A. Vecchi, M. Winton, and R. G. Gudgel, 2014: Importance of initial conditions in seasonal predictions of Arctic sea ice extent. Geophys. Res. Lett., 41, 5208-5215, https://doi.org/10.1002/2014GL060799.

Peterson, K. A., A. Arribas, H. Hewitt, A. Keen, D. Lea, and A. McLaren, 2015: Assessing the forecast skill of Arctic sea ice extent in the GloSea4 seasonal prediction system. Climate Dyn., 44, 147-162, https://doi.org/10.1007/s00382-014-2190-9.

Petty, A. A., M. M. Holland, D. A. Bailey, and N. T. Kurtz, 2018: Warm Arctic, increased winter sea ice growth? Geophys. Res. Lett., 45, 12 922-12 930, https://doi.org/ 10.1029/2018GL079223.

Pohlmann, H., M. Botzet, M. Latif, A. Roesch, M. Wild, and P. Tschuck, 2004: Estimating the decadal predictability of a coupled AOGCM. J. Climate, 17, 4463-4472, https://doi.org/ $10.1175 / 3209.1$

Schröder, D., D. L. Feltham, D. Flocco, and M. Tsamados, 2014: September Arctic sea-ice minimum predicted by spring meltpond fraction. Nat. Climate Change, 4, 353-357, https:// doi.org/10.1038/nclimate2203.

Schweiger, A., R. Lindsay, J. Zhang, M. Steele, H. Stern, and R. Kwok, 2011: Uncertainty in modeled Arctic sea ice volume. J. Geophys. Res., 116, C00D06, https://doi.org/10.1029/2011JC007084.
Sigmond, M., J. C. Fyfe, G. M. Flato, V. V. Kharin, and W. J. Merryfield, 2013: Seasonal forecast skill of Arctic sea ice area in a dynamical forecast system. Geophys. Res. Lett., 40, 529534, https://doi.org/10.1002/grl.50129.

Stroeve, J. C., and D. Notz, 2018: Changing state of Arctic sea ice across all seasons. Environ. Res. Lett., 13, 103001, https:// doi.org/10.1088/1748-9326/aade56.

— A. D. Crawford, and S. Stammerjohn, 2016: Using timing of ice retreat to predict timing of fall freeze-up in the Arctic. Geophys. Res. Lett., 43, 6332-6340, https://doi.org/10.1002/2016GL069314.

Theocharis, D., S. Pettit, V. Sanchez Rodrigues, and J. Haider, 2018: Arctic shipping: A systematic literature review of comparative studies. J. Transp. Geogr., 69, 112-128, https:// doi.org/10.1016/j.jtrangeo.2018.04.010.

Tietsche, S., J. J. Day, V. Guemas, W. J. Hurlin, S. Keeley, D. Matei, R. Msadek, M. Collins, and E. Hawkins, 2014: Seasonal to interannual Arctic sea ice predictability in current global climate models. Geophys. Res. Lett., 41, 1035-1043, https://doi.org/10.1002/2013GL058755.

Wang, W., M. Chen, and A. Kumar, 2013: Seasonal prediction of Arctic sea ice extent from a coupled dynamical forecast system. Mon. Wea. Rev., 141, 1375-1394, https://doi.org/10.1175/ MWR-D-12-00057.1.

Zhang, J., and D. A. Rothrock, 2003: Modeling global sea ice with a thickness and enthalpy distribution model in generalized curvilinear coordinates. Mon. Wea. Rev., 131, 845-861, https://doi.org/ 10.1175/1520-0493(2003)131<0845:MGSIWA > 2.0.CO;2. 